\title{
QbD Based Approach to Enhance the In-Vivo Bioavailability of Ethinyl Estradiol in Sprague-Dawley Rats
}

\author{
Trupti Ashok Powar ${ }^{1}$ and Ashok Ananda Hajare ${ }^{1, *}$ \\ ${ }^{1}$ Department of Pharmaceutics, Bharati Vidyapeeth College of Pharmacy, Kolhapur Maharashtra-416013, India. \\ *Corresponding author: E-mail: ashok.hajare@bharatividyapeeth.edu \\ Mobile - 8788409138
}

Received: 07-24-2019

\begin{abstract}
Lyophilized nanosuspension of poorly soluble Ethinyl estradiol (EE) was fabricated to enhance its solubility and bioavailability using a quality-by-design $(\mathrm{QbD})$ approach. With the help of the Ishikawa diagram, prospective risk factors were identified and screened by Placket-Burman design to investigate the effects of formulation and process variables on dependent variables. The number of cycles (X4), the concentration of soya lecithin (X5) and the concentration of tween 80 (X7) were identified as significant factors $(\mathrm{P}<0.05)$, which were further optimized using Central Composite Design. The mean particle size, zeta potential, drug content and entrapment efficiency of optimized lyophilized EE nanosuspension (EENPs) was $220 \pm 0.37 \mathrm{~nm},-19.3 \pm 6.73 \mathrm{mV}, 92.23 \pm 0.45 \%, 99.52 \pm 0.52 \%$, respectively. Significantly, EENPs enhances $\mathrm{C}_{\max }$ and $\mathrm{AUC}_{0-\mathrm{t}}$ by 1.5, 1.7 folds and relative bioavailability by 2 -fold with its distribution being at higher concentrations in the liver, spleen, and stomach. Thus, QbD based approach for the development of nanosuspension could be an absolute, optimistic approach to identify the critical process parameters and critical quality attributes.
\end{abstract}

Keywords: Quality by design; Lyophilized nanosuspension of ethinyl estradiol; Central Composite Design; PlackettBurman Design; Bioavailability and stability.

\section{Introduction}

Ethinyl estradiol (EE), (17a)-19-norpregna-1, 3, 5-(10) trien-20-yne-3, 17-diol is an estrogenic component, which is widely used in hormone replacement therapy and as an oral contraceptive. ${ }^{1-3}$ It is also known for its effectiveness to treat breast cancer, prostate cancer, ${ }^{4-9}$ as high-dose of $\mathrm{EE}$ is effective for first-line treatment and also for treatment after endocrine resistance to aromatase inhibitors and tamoxifen. ${ }^{10} \mathrm{EE}$ is yellow to white crystalline powder, insoluble in water but soluble in ether, ethanol, acetone, chloroform, and dioxane. It is also found to be soluble in dilute alkaline solutions and vegetable oils. It is available in small doses alone or with a combination. ${ }^{11}$ However, EE has a poor aqueous solubility, which is the biggest hurdle in the clinical application for cancer treatment. Lower solubility leads to complications in drug delivery like unpredictable absorption and thus deplorable oral bioavailability. Due to extensive first-pass hepatic metabolism after oral administration, EE has $40 \%$ of systemic bioavailability due to its initial conjugation with the gut wall. ${ }^{11}$ There- fore, solubility enhancement of EE should be considered first for its development.

Various traditional approaches are used to enhance the solubility of poorly soluble drugs which includes micronization, use of cyclodextrin and co-solvents. ${ }^{11}$ But unfortunately, the problem of bioavailability remains unsolved in many cases. In the case of micronization, sufficient surface area is not produced in order to enhance the dissolution velocity of poorly water-soluble drugs. Thus, industries are moving forward towards nanonization (formulation of nanosuspension) from micronization. ${ }^{12}$

In scientific research, nanomedicines have attained the topmost place and their application as medicines have gained vital place due to its larger surface area as compared to its particle size. ${ }^{13,14}$ In last few decades, new drugs fail to reach the market due to their vital issues related to solubility, dissolution, and bioavailability, maybe due to lack of dose proportionality, uncertain drug absorption, poor dissolution, and inter-intra subject variability. Thus it becomes a complicated task for most of the 
scientist in clinical research to fulfill such lacuna. ${ }^{15,16,17}$ Fabrication of practically water-insoluble or very slightly soluble drugs to nanosuspension is in greater demand due to consequences of the previously mentioned problems. ${ }^{18}$ Nanosuspension (NS) is a submicron colloidal suspension, which consists of dispersed drug particles in water along with polymer as stabilizer or surfactant through top-down or bottom-up techniques. ${ }^{19,20} \mathrm{NS}$ is an emerged potential solubility enhancement technique since last decade's, ${ }^{21}$ in which the poorly soluble drugs without any matrix materials are suspended in dispersion. NS are fabricated using drugs with a small amount of stabilizer below critical micelle concentration (CMC) to stabilize the formulation. Generally, most of the nanoparticle formulations are developed using a larger concentration of excipients but it is not the case with NS, as its most part is a drug. Beyond the use of lower concentration of stabilizers in the formulation of NS, it makes toxicity issues negligible and offers better physical and chemical stability with ease of scale-up as compared to amorphous form. NS enhances the solubility of poorly soluble drugs in aqueous as well as non-aqueous media. Increased solubility leads to an increase in the rate of flooding of drug and hence reaches maximum plasma level at a faster rate. The reduced particle size makes these drugs suitable to be administered by the intravenous route without blocking the blood capillaries. This technique applies to the molecules that have poor permeability, poor solubility, or both (BCS class II and IV drugs). ${ }^{22-25}$ For the productive development of NS, various methods have been reported to be employed that include top-down techniques such as media milling, high-pressure homogenization, and sonication, and bottom-up technique of nanoprecipitation. To enhance the physical stability of NS, numerous solidification techniques have been used which includes lyophilization, spray drying, rotary evaporation and many more based on the physical properties of drugs and characteristics of the final formulation. ${ }^{26-29}$ Out of all techniques listed above, lyophilization is predominately used for solidification of NS, as it offers several merits which include suitability for drying of thermolabile drugs, easy reconstitution of the formulation before use, enhanced storage stability, and production of high-value products without excessive damage. ${ }^{21}$ Thus the development of EE in lyophilized NS form can be a useful tool to tackle the aforesaid problems.

The usage of principles of quality by design (QbD) was proposed by the International Conference on Harmonization (ICHQ8) of technical requirements in the formulation of pharmaceutical products. ${ }^{31}$ The major challenges faced during the formulation of NS are manufacturing variability, due to lack of understanding of the effect of critical material attributes (CMAs) and critical processing parameters (CPPs), attainment of small size, and narrow polydispersity index (PDI). Due to a lack of understanding and manufacturing variabilities, there is an increase in the cost of a nanoparticulate drug delivery system (NDDS). NDDS is well known for its toxicities due to the faster onset of action, permeability, increased solubility, and bioavailability. Hence, the aim of the present study was to prepare the ethinyl estradiol NS with QbD approach in order to obtain the effect of CMAs and CPPs on critical quality attributes (CQAs), improvement of safety and quality of the formulation, reduction in the manufacturing variability, and controlling the manufacturing cost. ${ }^{30}$

For the planning of experiments, usage of statistical design of experiments (DOE) is an efficient tool. Plackett Burman (PB) of screening experiment and the Central Composite Design (CCD) of response surface methodology (RSM) are a well-set approach for optimization and development of pharmaceutical formulations, allowing acquisition of maximal data from a lesser number of well-designed experimental batches. ${ }^{15}$

Initially, all the potential independent variables were identified using Plackett-Burman design. Then a predictive model for critical response variables was constructed for the determination of optimized value using CCD to develop highly stable and soluble EENPs. Developed EENPs were dried using lyophilizer to stabilize the NS. The resultant EENPs were evaluated for its saturation solubility, zeta potential, particle size, polydispersity index, surface topographical studies, dissolution efficiency, in-vivo bioavailability, and stability studies.

\section{Experimental}

\section{1. Materials}

EE and Methotrexate were gifted by Cipla Ltd. Goa, (India). Tween 80 and mannitol was procured from Merck Specialities Pvt. Ltd. Mumbai, (India). Soya lecithin (SL) (Phospholipon ${ }^{\circ} 90 \mathrm{H}$ ) was gifted by Lipoid GmbH (Germany). HPLC grade methanol was procured from Thermo Fisher Scientific Pvt. Ltd. Mumbai, (India). Double distilled water was prepared in the laboratory and all other reagents used in the study were of analytical grade.

\section{2. Methods}

\section{2. 1. Screening of the Stabilizer and Polymers for EENPs}

For the preparation of EENPs, suitable stabilizers were screened from 20 stabilizers as follows,

\section{2. 1. 1. Suspending Effect of Stabilizers}

Stabilizers and polymers were selected on the basis of suspending concentration of stabilizers namely tween 80, cremophor EL-40, soya lecithin (SL), hydroxypropyl methylcellulose (HPMC), sodium lauryl sulphate (SLS), poloxamer 188 (F68), poloxamer 407, polyethylene glycol (PEG) 6000, sodium deoxycholate (SDS), span 80, polyvi- 
nyl pyrrolidone (PVP) K 30, Carbomer 940, and/or their mixtures on EE. About $0.5 \mathrm{mg}$ of EE was added to $0.2 \%$ $(\mathrm{w} / \mathrm{v})$ of surfactant solutions, followed by shearing with a high-speed homogenizer (IKA RW 20 Digital, Hyland Scientific, USA) at 3,000 rpm for $1.5 \mathrm{~h}$ and centrifugation was done at $4000 \mathrm{rpm}$ for $30 \mathrm{~min}$. The supernatant obtained was diluted with possible solvents and the drug content was determined by ultraviolet-visible spectrophotometer (UV-Vis, Jasco V-530, Japan) at $280 \mathrm{~nm}$. The stabilizers that showed an optimal suspending effect on EE, smaller particle size and lesser sedimentation rate were optimized as the compositions for fabricating NS. ${ }^{25,33,34}$

\section{2. 1. 2. Docking Tool and Algorithm}

Molecular docking was used to predict the virtual interactions between EE, and stabilizers systems. VLife MDS version 4.6 was used for molecular docking studies. The structures of all the stabilizers and drug were drawn in a $2 \mathrm{D}$ format which was followed by $3 \mathrm{D}$ conversion and was finally optimized for docking study. Biopredicta is a docking algorithm based on the genetic design, and it was used to predict and study modes of interactions between two compounds. The possible interactions were optimized based on receptor-ligand binding geometry within chemical structures. The molecular interaction between EE and stabilizers were analyzed to prove the stabilizers ability to enhance drug solubility and NS stability.

\section{2. 2. Formulation and Lyophilization of EENPs}

EENPs were fabricated using high-pressure homogenizer (HPH) (Panda PLUS 2000, GEA Niro Soavi, Germany). To prevent blocking of the homogenizer valve, the coarse powder of EE $(0.5 \mathrm{mg} / \mathrm{mL})$ was first eventually dispersed in an aqueous stabilizer solution of tween $80(0.15 \% \mathrm{v} / \mathrm{v})$ and SL $(30 \mathrm{mg})$ using digital ho- mogenizer at $3000 \mathrm{rpm}$ for $1 \mathrm{~h}$ to form primary nanosuspension. The primary nanosuspension was further processed through an $\mathrm{HPH}$ with three homogenization cycles at 250, 700, and 1200 bars, followed by maximum cycles at 1500 bars. By varying the number of homogenization cycles and keeping process temperature constant at $25{ }^{\circ} \mathrm{C}$ different particle size EENPs were obtained. ${ }^{34}$ Liquid EENPs formulations were processed for lyophilization using laboratory freeze dryer (Freezone12, Labconco, MO, USA) using mannitol $(6 \% \mathrm{w} / \mathrm{w})$ as a cryoprotectant. The formulations were pre-freezed at -30 ${ }^{\circ} \mathrm{C}$ for $12 \mathrm{~h}$. The primary drying was performed at $-53^{\circ} \mathrm{C}$ and $0.016 \mathrm{mBar}$ for $24 \mathrm{~h}$. The secondary drying was performed at $10^{\circ} \mathrm{C}$ for $8 \mathrm{~h}$ and was followed by drying at 25 ${ }^{\circ} \mathrm{C}$ for $4 \mathrm{~h}$ with a gradual increase in temperature at $1{ }^{\circ} \mathrm{C} /$ min. Finally, the temperature of the cold trap was maintained at $-53{ }^{\circ} \mathrm{C}$ until completion of the drying process. Resultant powder of EENPs was further used for subsequent evaluation studies. ${ }^{3-36}$

\section{2. 3. Design of Experiments}

\section{2. 3. 1. Quality Target Product Profile (QTPP)}

To determine the quality target product profile (QTPP), risk, regulatory, scientific and practical aspects are considered. The main goal of the study is the determination of target product quality profile (TPQP) and target product profile. Control space can also be helped to establish the region of operability. CMAs and CPPs were selected in this study to achieve the predefined target. The identified QTPP, CMAs, and CPPs are given in Table $1 .{ }^{30}$

\section{2. 3. 2. Ishikawa Diagram for Risk Assessment}

Ishikawa diagram was constructed to identify the formulation variables along with process variables of $\mathrm{HPH}$ technique and to evaluate their ability to influence the CQAs

Table 1. Study target with CMAs and CPPs

\begin{tabular}{|c|c|c|c|c|}
\hline \multicolumn{2}{|c|}{ QTPP } & TPQP & $\begin{array}{c}\text { CMAs } \\
\text { Materials }\end{array}$ & $\begin{array}{c}\text { CPPs } \\
\text { Parameters }\end{array}$ \\
\hline Formulation type & Nanosuspension & $\begin{array}{l}\text { - Particle size } \\
\text { - PDI } \\
\text { Method of assessment: Malvern Zetasizer } \\
\text { - Particle shape and morphology } \\
\text { Method of assessment: SEM }\end{array}$ & Soya lecithin (mg) & No. of cycles \\
\hline $\begin{array}{c}\text { Oral } \\
\text { bioavailability }\end{array}$ & $\begin{array}{l}\text { Enhancement of } \\
\text { oral bioavailability }\end{array}$ & $\begin{array}{l}\text { - Saturation solubility } \\
\text { Method of assessment: Orbital shaker } \\
\text { - In vitro drug release } \\
\text { Method of assessment: USP type II apparatus } \\
\text { - In vivo studies } \\
\text { Method of assessment: an indirect method } \\
\text { for the assessment of drug in rat plasma }\end{array}$ & Tween 80 (\% v/v) & \\
\hline
\end{tabular}

* $\mathrm{TPQP}=$ target product quality profile; $\mathrm{TPP}=$ target product profile; $\mathrm{CMA}=$ critical material attribute; $\mathrm{QTPP}=$ quality target product profile; $\mathrm{CPP}$ = critical processing parameter; SEM = scanning electron microscopy; USP = United States Pharmacopeia; PCS = photon correlation spectroscopy;

PDI = polydispersity index. 
of EENPs. This approach helps to enhance the quality, safety and efficacy of the developed formulation. On the basis of prior studies, experimental trials, literature survey and the application of failure mode effect analysis method, the major quality attributes, namely drug content, entrapment efficiency and average particle size, were considered as CQAs of EENPS, which would likely affect the medicinal efficacy of nanoparticles drug delivery. The Ishikawa diagram illustrates the effect of CMAs and CPPs on TPQP. Ishikawa diagram of EENPs showed that formulations and process variables may affect the properties of nanoparticles and thus, such variables should be included in later studies..$^{29,30}$

\section{2. 3. 3. Plackett-Burman Design for Risk Analysis}

Process variables that affect the CQAs of EENPs formulation were screened by a group of experiments using Plackett-Burman (PB) screening design for the formulation of EENPs using HPH. We can screen a large number of factors with a few runs by using the PB design. ${ }^{37}$ Another important part of $\mathrm{PB}$ designs was the option of dummies, the component whose level does not change. ${ }^{38}$ Only main effects can be estimated by the PB design, as they are the resolution of three designs. From the large set of experimental factors, PB designs are typically used to identify a few but significant factors. ${ }^{37}$ Design-Expert (Version 11.0.5.0, Stat-Ease Inc., MN), involving eight independent variables, generated 12 experiment trials. The independent variables screened were, speed of high speed homogenizer (primary nanosuspension) (X1), time of homogenizer (primary nanosuspension) (X2), homogenization pressure (X3), number of cycles (X4), concentration of SL (X5), concentration of SLS (X6), concentration of tween 80 (X7) and concentration of EE (X8). The response variables selected were particle size (Y1), drug content (Y2) and en- trapment efficiency (Y3) based on trials drawn during preliminary batches (Table 2).

According to the runs or trials arranged by design expert software, experiments were performed in randomized order. The values of the response variables were the mean of three measurements. To estimate the significance of interactions and main effects, analysis of variance (ANOVA) was used. Factors that show a negligible effect on the response variables at $95 \%$ of significance level were screened and the remaining factors that have an impact on response variables were further optimized by CCD.

\section{2. 3. 4. Central Composite Design for Optimization of EENPs}

After identification of critical formulation and process variables using $\mathrm{PB}$ screening design, $5^{3} \mathrm{CCD}$ response surface methods were used to inspect the optimum levels of the variables. This consisted of two groups of design points, which includes two-level factorial design points as -1 and +1 , axial or star points as $-\alpha$ and $+\alpha$ along with center points as 0 . Thus, the effect of three independent variables viz., the concentration of tween 80 (A), the concentration of SL (B) and the number of cycles (C) was studied at five different levels, with the coding of $-\alpha,-1,0$, +1 , and $+\alpha$. Alpha value, 1.6817 fulfills the rotatability in the CC design. Dependent variables selected for the formulation of EENPs by CCD were particle size (Y1), drug content (Y2) and entrapment efficiency (Y3). Table 3 suggests the coded and actual values of variables. The Design Expert ${ }^{\circledR}$ software was used to generate a CCD matrix with 20 runs, which includes six replicated center points, one axial point and one replication of fractional point.

To obtain a CCD matrix, the 20 EENPs trial batches were formulated and evaluated for their responses with

Table 2. Plackett-Burman design with independent variables and their responses.

\begin{tabular}{ccccc}
\hline & & Factors & Levels \\
& & High & Low \\
\hline $\mathrm{X} 1$ & $:$ & Speed of Homogenizer (Preliminary Stage) $(\mathrm{rpm})$ & 8000 & 6000 \\
$\mathrm{X} 2$ & $:$ & Time of Homogenizer (Preliminary Stage) $(\mathrm{min})$. & 45 & 30 \\
$\mathrm{X} 3$ & $:$ & Homogenization Pressure (Bars $\left.{ }^{*} 1000\right)$ & 25 & 5 \\
$\mathrm{X} 4$ & $:$ & Number of Cycles & 25 & 5 \\
$\mathrm{X} 5$ & $:$ & Concentration of soya lecithin (mg) & 30 & 15 \\
$\mathrm{X} 6$ & $:$ & Concentration of sodium lauryl sulphate $(\mathrm{mg})$ & 30 & 15 \\
$\mathrm{X} 7$ & $:$ & Concentration of tween 80 (\% v/v) & 0.30 & 0.15 \\
$\mathrm{X} 8$ & $:$ & Concentration of Ethinyl estradiol (mg) & 60 & 40 \\
\hline
\end{tabular}

Table 3. $5^{3}$ Central composite designs with independent variables and their responses.

\begin{tabular}{|c|c|c|c|c|c|c|c|}
\hline & & \multirow{2}{*}{ Factors } & \multicolumn{5}{|c|}{ Levels } \\
\hline & & & $-\alpha$ & -1 & $\mathbf{0}$ & +1 & $+\alpha$ \\
\hline A & $:$ & Concentration of Tween 80 (\% v/v) & 0.10 & 0.15 & 0.20 & 0.25 & 0.30 \\
\hline B & $:$ & Concentration of Soya lecithin (mg) & 10 & 15 & 20 & 25 & 30 \\
\hline $\mathrm{C}$ & $:$ & Number of cycles & 10 & 20 & 30 & 40 & 50 \\
\hline
\end{tabular}

Powar and Hajare: QbD Based Approach to Enhance the In-Vivo ... 
model fitting. ${ }^{38}$ For optimization of the current study, various response surface methodology (RSM) were computed and polynomial models were generated, with interaction and quadratic terms for all the response variables using multiple linear regression analysis (MLRA) approach. Additionally, the output files generated by the Design-Expert software were used to construct 2-D contour plots. ${ }^{40}$

\section{2. 3. 5. Process Analytical Technology (PAT) - Particle Size Analysis, Entrapment Efficiency and Drug Content}

Particle size analysis of fabricated EENPs was measured using Zetasizer 300 HAS (Malvern Instruments, Malvern, UK), while entrapment efficiency and drug content was determined using UV-visible spectrophotometer (Jasco V-530, Japan ) at $280 \mathrm{~nm}$ wavelength, which was used for PAT for particle size, entrapment efficiency and drug content analysis. ${ }^{30,35,41}$

\section{2. 4. Characterization of Optimized Lyophilized EENPs}

\section{2. 1. Particle Size, Polydispersity Index and Particle Charge Analysis}

Particle size, zeta potential and polydispersity index (PDI) of optimized EENPs was measured using Zetasizer 300 HAS (Malvern Instruments, Malvern, UK). Prior to size determination, lyophilized nanosuspension was redispersed in distilled water. Data obtained were mean average values of three independent samples that are prepared under same formulation conditions. ${ }^{35,41}$

\section{2. 4. 2. Scanning Electron Microscopy (SEM)}

The SEM was used to study the surface morphology of EENPs which examines sphericity, discreteness and surface properties of NPs. SEM studies were carried out using SEM (JEOL JSM-6360, Japan) at $20 \mathrm{kV}$ accelerating voltage and high vacuum. Before analysis, lyophilized EENPs were first placed on two-sided carbon tape and then, sputtered with gold-palladium alloy up to $3-5 \mathrm{~nm}$ of thickness. ${ }^{32,34}$

\section{2. 4. 3. Saturation Solubility Studies}

Saturation solubility was performed by adding an excess quantity of pure drug (EE) and optimized lyophilized EENPs in $10 \mathrm{ml}$ of distilled water. Then, samples were agitated in an orbital shaker (Remi instruments limited, Mumbai) for $48 \mathrm{~h}$ at $25^{\circ} \mathrm{C}$. The samples were then centrifuged to remove the solid content as a residue and the amount of drug present in the supernatant layer was analyzed spectrophotometrically using UV-visible spectrophotometer at $280 \mathrm{~nm} .{ }^{38}$

\section{2. 4. 4. Fourier Transform Infrared Spectroscopy (FTIR)}

FTIR of a drug (EE), physical mixture (PM) and optimized lyophilized EENPs was analyzed using FTIR spec- trophotometer (Agilent CARY 630 FTIR) to study the compatibility between drug and stabilizers. Each sample was placed on a diamond ATR crystal and was analyzed using Agilent resolutions pro software. Each spectrum of samples was collected from an average of 21 single scans at $4 \mathrm{~cm}^{-1}$ resolution in the absorption area of $800-4000$ $\mathrm{cm}^{-1} \cdot 32$

\section{2. 4. 5. In-Vitro Drug Release}

Dissolution studies on EE powder and optimized EENPs were carried out using USP type-II apparatus. Weighed quantities of samples were transferred into dissolution apparatus (Electro lab TDT-08 L, India) containing $900 \mathrm{~mL}$ of simulated gastric fluid (SGF) as a medium with $\mathrm{pH}$ 1.2. The shaft speed was set to $50 \mathrm{rpm}$ at medium temperature $37 \pm 0.5^{\circ} \mathrm{C}$. Samples ( $5 \mathrm{~mL}$ each) were withdrawn at 10,20,30,40,50 and 60 min time interval and the fresh buffer was added to maintain the sink conditions. The samples were collected and filtered using Whatman filter paper $(0.25 \mu \mathrm{m}$, Whatman Inc., USA $)$ and analyzed using UV spectrophotometer at $280 \mathrm{~nm}^{34}$

\section{2. 6. Pharmacokinetic and Biodistribution Study in Sprague- Dawley Rats}

The pharmacokinetic (PK) and biodistribution studies were performed using Sprague- Dawley rats, with mean weight 200-220 g, purchased from Global Bioresearch Solutions Pvt. Ltd., Pune. The Institutional Animal Ethics Committee (IAEC) of Bharati Vidyapeeth College of Pharmacy, Kolhapur, Maharashtra, India (BVCPK / CPCSEA / IAEC / 01/14/2017-2020) has approved the study protocol. Prior to the experiment, rats were kept on fast overnight with free access to water ad libitum. These rats were randomly divided into three groups $(n=3)$. The group I was served with optimized EENPs (test group), group II was treated with EEAQD (standard group), whereas group III was given a normal saline solution (control group). On the day of the experiment, samples and dosing $(0.5 \mathrm{mg} / \mathrm{kg})$ of optimized EENPs and EEAQD were prepared freshly and administered orally to rats using oral feeding cannula. Under mild anesthesia, blood samples $(0.5 \mathrm{~mL})$ were collected at the time intervals of $0,2,3,4,6,12,24,36$ and $48 \mathrm{~h}$ from the retro-orbital vein and were transferred into a tube containing EDTA. Immediately blood samples were centrifuged at $3,000 \mathrm{rpm}$ for $10 \mathrm{~min}$ at $4{ }^{\circ} \mathrm{C}$ to separate plasma and were stored at $-20^{\circ} \mathrm{C}$ until analysis.

The animals were sacrificed $(\mathrm{n}=3)$ by cervical dislocation. The drug distribution in vital organs is measured after $72 \mathrm{~h}$ of dose administration. Tissue samples from liver, spleen, heart, brain, stomach, lungs, and kidney were homogenized quickly followed by centrifugation, and clear tissue samples obtained were stored at $-20^{\circ} \mathrm{C}$ before analysis. The blood plasma and tissue samples were mixed with $20 \mu \mathrm{L}$ internal standard (methotrexate) solution (5 $\mu \mathrm{g} / \mathrm{mL}$ ). Deproteinization was done by adding $100 \mu \mathrm{L}$ acetonitrile in $50 \mu \mathrm{L}$ plasma sample, and $300 \mu \mathrm{L}$ acetonitrile to 
$200 \mu \mathrm{L}$ of clear tissue homogenates followed by cold centrifugation at $6,000 \mathrm{rpm}$ for $15 \mathrm{~min}$ at $4{ }^{\circ} \mathrm{C}$. Transparent supernatant obtained was filtered using $0.20 \mu \mathrm{m}$ syringe filter and injected into the HPLC system for determining EE content in blood plasma and tissue samples..$^{35,36}$

\section{HPLC Analysis}

EE content was analyzed using reverse phase-HPLC system with UV detector and with a pump (Model Jasco PU-2080, intelligent HPLC pump). A reverse phase C18 column $(150 \mathrm{~mm} \times 4.6 \mathrm{~mm}$, pore size $5 \mu \mathrm{m}$, Phenomenex) was used to achieve chromatographic separation. The mobile phase optimized was 70:30 v/v mixture of water and acetonitrile. The separation was carried out under an isocratic condition with a constant flow rate of $1.0 \mathrm{~mL} / \mathrm{min}$, with $20 \mu \mathrm{L}$ injection volume, at a column temperature of $25^{\circ} \mathrm{C}$, and wavelength of $280 \mathrm{~nm}$. The calibration curve for $\mathrm{EE}$ in plasma was linear within the concentration range $15-100 \mu \mathrm{g} / \mathrm{mL}$ with correlation coefficient $\mathrm{R}^{2}=0.9932$, with methotrexate as an internal standard. The experimental data are expressed as mean \pm SD and the level of significance is taken as $\mathrm{P}<0.05 .{ }^{42}$

\section{Pharmacokinetic Analysis}

The PK analysis of plasma concentration-time profile was carried out by a non-compartmental model using Microsoft Excel (Microsoft office 2016). The PK parameters were directly obtained from plasma data, including $\mathrm{AUC}_{0-\mathrm{t}}$ (area under the plasma concentration-time curves), $\mathrm{C}_{\max }$ (maximum plasma concentration), $\mathrm{T}_{\max }$ (the time to reach maximum plasma concentration), $\mathrm{t}_{1 / 2}$ (elimination halflife), MRT (mean residence time), $\mathrm{K}_{\mathrm{el}}$ (elimination rate constant), $\mathrm{VD}$ (volume of distribution), $\mathrm{Cl}$ (clearance), and $\mathrm{F}_{\text {rel }}$ (relative bioavailability). $\mathrm{F}_{\text {rel }}$ of lyophilized EENPs after oral administration was computed according to the following formula with the EEAQD as a reference,

$$
\mathrm{F}_{\text {rel }}=\frac{\text { AUC test }}{\text { AUC reference }} \times 100
$$

All data were expressed as mean \pm SD and the level of significance was taken as $\mathrm{P}<0.05 .^{32}$

\section{2. 4. 7. Stability Studies}

The stability studies of optimized lyophilized EENPs and liquid EENPs were performed as per ICH Q1A (R2) guidelines. The formulations were wrapped in aluminum foils and stored at $4{ }^{\circ} \mathrm{C}$ (in refrigerator), room temperature (RT) in shadow and $40 \pm 2{ }^{\circ} \mathrm{C}$ temperature and $75 \pm$ $5 \%$ relative humidity (in the stability chamber) for six months and evaluated at specific time interval for drug content and particle size to study the chemical and physical stability. ${ }^{40}$

\section{2. 4. 8. Statistical Analysis}

The data generated as an outcome of experimental work was analyzed using multilinear regression analysis, ANOVA and lack-of-fit tests. To test the statistical significance, wherever applicable, student's t-test was used and expressed as mean $\pm S D(n=3)$.

Table 4. Suspending concentrations and particle size of ethinyl estradiol in different stabilizer systems for formulation of nanosuspension.

\begin{tabular}{|c|c|c|c|c|c|}
\hline Stabilizers ${ }^{\star}$ & $\begin{array}{l}\text { Conc. of } E E^{* *} \\
(\mu \mathrm{g} / \mathrm{mL})\end{array}$ & $\begin{array}{l}\text { Particle size } \\
\text { (nm) }\end{array}$ & Stabilizers $^{*}$ & $\begin{array}{l}\text { Conc. of } E E^{* *} \\
(\mu \mathrm{g} / \mathrm{mL})\end{array}$ & $\begin{array}{c}\text { Particle size }{ }^{* *} \\
(\mathrm{~nm})\end{array}$ \\
\hline Tween 80 & $189.75 \pm 0.05$ & $311.33 \pm 2.56$ & SL/SDS & $19 \pm 0.09$ & $806.65 \pm 1.88$ \\
\hline $\begin{array}{l}\text { Sodium lauryl } \\
\text { sulphate (SLS) }\end{array}$ & $184.60 \pm 0.02$ & $341.23 \pm 2.89$ & SLS/ Poloxamer 407 & $183.9 \pm 0.02$ & $456.52 \pm 1.45$ \\
\hline Poloxamer 188 & $155.40 \pm 0.01$ & $389.56 \pm 2.45$ & Poloxamer 407/ Tween 80 & $119.66 \pm 0.08$ & $532.02 \pm 1.65$ \\
\hline Poloxamer 407 & $111.14 \pm 0.00$ & $303.56 \pm 2.74$ & Tween 80/ Carbomer 940 & $155.4 \pm 0.03$ & $625.78 \pm 2.01$ \\
\hline HPMC-K5 & $15.28 \pm 0.09$ & $896.12 \pm 2.65$ & Tween 80/ SLS & $95.33 \pm 0.04$ & $436.22 \pm 2.01$ \\
\hline Soya lecithin (SL) & $204.27 \pm 0.01$ & $291.23 \pm 4.25$ & SDS/ Poloxamer 407 & $10 \pm 0.04$ & $345.65 \pm 2.42$ \\
\hline Cremorphor EL- 40 & $119.66 \pm 0.04$ & $596.56 \pm 3.56$ & Tween 80 / HPMC-K5 & $48.52 \pm 0.06$ & $765.45 \pm 4.56$ \\
\hline $\begin{array}{l}\text { Sodium } \\
\text { deoxycholate (SDS) }\end{array}$ & $15.65 \pm 0.05$ & $356.45 \pm 3.89$ & Tween 80/ SDS & $63 \pm 0.06$ & $456.09 \pm 3.54$ \\
\hline Carbomer 940 & $46.44 \pm 0.09$ & $478.55 \pm 4.23$ & Tween 80/ SL & $77.92 \pm 0.33$ & $346.89 \pm 2.31$ \\
\hline PVP K30 & $54.96 \pm 0.03$ & $689.49 \pm 4.66$ & Poloxamer $407 /$ SL & $119.56 \pm 0.10$ & $374.88 \pm 2.90$ \\
\hline PEG 6000 & $165.99 \pm 0.54$ & $596.89 \pm 2.96$ & Tween 80/SDS/ Poloxamer 407 & $54.66 \pm 0.02$ & $567.09 \pm 3.04$ \\
\hline Span 80 & $175.89 \pm 0.08$ & $665.96 \pm 2.36$ & Span 80/ Poloxamer 407/SDS & $37.49 \pm 0.09$ & $678.02 \pm 2.45$ \\
\hline $\begin{array}{l}\text { Poloxamer } \\
188 \text { / SLS }\end{array}$ & $180.85 \pm 0.02$ & $459.56 \pm 2.03$ & Tween $80 /$ Poloxamer 188/ SLS & $85.44 \pm 0.02$ & $654.33 \pm 2.41$ \\
\hline $\begin{array}{l}\text { Tween } \\
\text { 80/Poloxamer } 188\end{array}$ & $165.36 \pm 0.17$ & $590.65 \pm 2.14$ & Tween 80/ SLS/ SL & $265.50 \pm 0.49$ & $321.32 \pm 1.62$ \\
\hline $\begin{array}{l}\text { Poloxamer } \\
407 / \text { Tween } 80\end{array}$ & $119.66 \pm 0.08$ & $788.21 \pm 2.66$ & & & \\
\hline
\end{tabular}

* All the ratios of different stabilizers in one system is represented as 1:1:1 (w/w/w) or 1:1 (w/w), except that the ratio of Tween 80 and Carbomer was $0.5: 1(\mathrm{w} / \mathrm{w}){ }^{* *}$ Results presented as means \pm SD $(\mathrm{n}=3)$ 


\section{Results and Discussion}

\section{1. Screening of the Stabilizer for EENPs}

\section{1. 1. Suspending Effect of Stabilizers on Drugs}

Stabilizers and polymers play a vital role in the fabrication of NS. The absence of appropriate stabilizer induces aggregation of nanosized drug particles due to high surface free energy of nanoparticles. A good stabilizer effectively reduces the surface energy of nanoparticles by dispersing them at an interface between water and particle to prevent particle aggregation in NS. They also prevent the Ostwald's ripening by producing ionic and/or steric barrier. For EENPs system, the appropriate stabilizer was screened by analyzing suspending effects, sedimentation rate and particle size of developed formulation and results obtained are reported in Table 4.

The combination of tween $80 /$ SLS/SL presented superior suspending effect on EE $(265.5 \pm 0.49 \mu \mathrm{g} / \mathrm{mL})$ compared to soya lecithin (SL) $(204.27 \pm 0.09 \mu \mathrm{g} / \mathrm{mL})$, tween $80(189.75 \pm 0.05 \mu \mathrm{g} / \mathrm{mL})$ and sodium lauryl sulphate (SLS) $(184.60 \pm 0.02 \mu \mathrm{g} / \mathrm{mL})$. While the particle size of the formulation prepared by Tween $80 /$ SLS/SL, SL, tween 80 and SLS was found to be $321.32 \pm 1.62,291.23 \pm 4.25$, $311.33 \pm 2.56$, and $341.23 \pm 2.89 \mathrm{~nm}$ respectively. Noteworthy, NS stabilized by SL, tween 80 and SLS did not produce stratification and sedimentation. The high surface free energy of nanosized particles makes NS a highly unstable thermodynamic system. Thus, based on particle size and suspending effect on EE, the combination of tween 80 and SL was selected as a good stabilizer system for fabrication of NS to obtain highest electric repulsion. ${ }^{12,25}$

\section{1. 2. Molecular Docking}

In the present study, the interaction between EE and stabilizers shows the ability of stabilizers to solubilize drug to enhance its stability. The virtual interactions between $\mathrm{EE}$ and stabilizers are shown in Fig. 1. EE and stabilizers con- tribute stronger interaction with each other by consuming lesser energy for binding, with strong hydrogen, hydrophobic and Vander Waal interactions. Thus, from these results, one can predict that stronger hydrogen bonding interaction between the EE and stabilizers like tween 80 and SL can virtually increase the solubility and stability of NS.

\section{2. Process Analytical Technology (PAT) - Particle Analysis, Entrapment Efficiency and Drug Content}

EENPs was prepared using soya lecithin as a polymer and tween 80 as a stabilizer with the applications of the QbD approach. The particle size, entrapment efficiency and drug content of fabricated EENPs was found to be in the range of 221-309 $\mathrm{nm}, 89.45-98.76 \%$, and 80.91 to $92.46 \%$, respectively. ${ }^{30}$

\section{3. Design of Experiments}

\section{3. 1. Ishikawa Diagram}

For identification of possible risks of process and formulation variables on the CQAs, viz., drug content, entrapment efficiency and particle size of EENPs, an Ishikawa diagram was established (Fig. 2). Eight possible risk factors were identified based on preliminary experiments and prior knowledge and were further evaluated using experimental designs. ${ }^{11}$

\section{3. 2. Plackett-Burman Design}

$\mathrm{PB}$ experimental design is conducted by incorporating eight factors, at two-levels, with twelve- run to screen the most significant formulation and process variables for the fabrication of EENPs. The formulations were piloted and the values of the responses obtained are reported in Table 5. For first response i.e. the particle size (Y1), the most significant and contributed factors were the concentration of tween 80 (X7), the concentration of SLS (X6), and the speed of

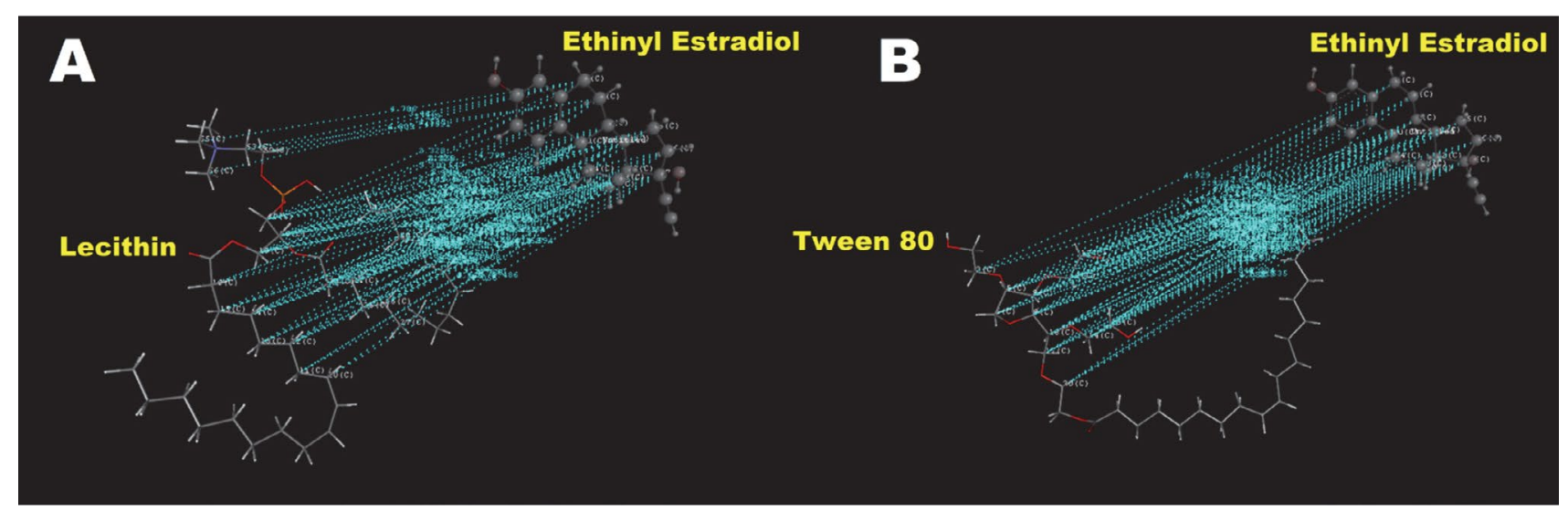

Figure 1. Docking study: a) interaction of ethinyl estradiol with soya lecithin, b) interaction of ethinyl estradiol with tween 80 .

${ }^{*}$ Colour code Light blue: Vander Waal interaction, Green: Hydrogen bonding 


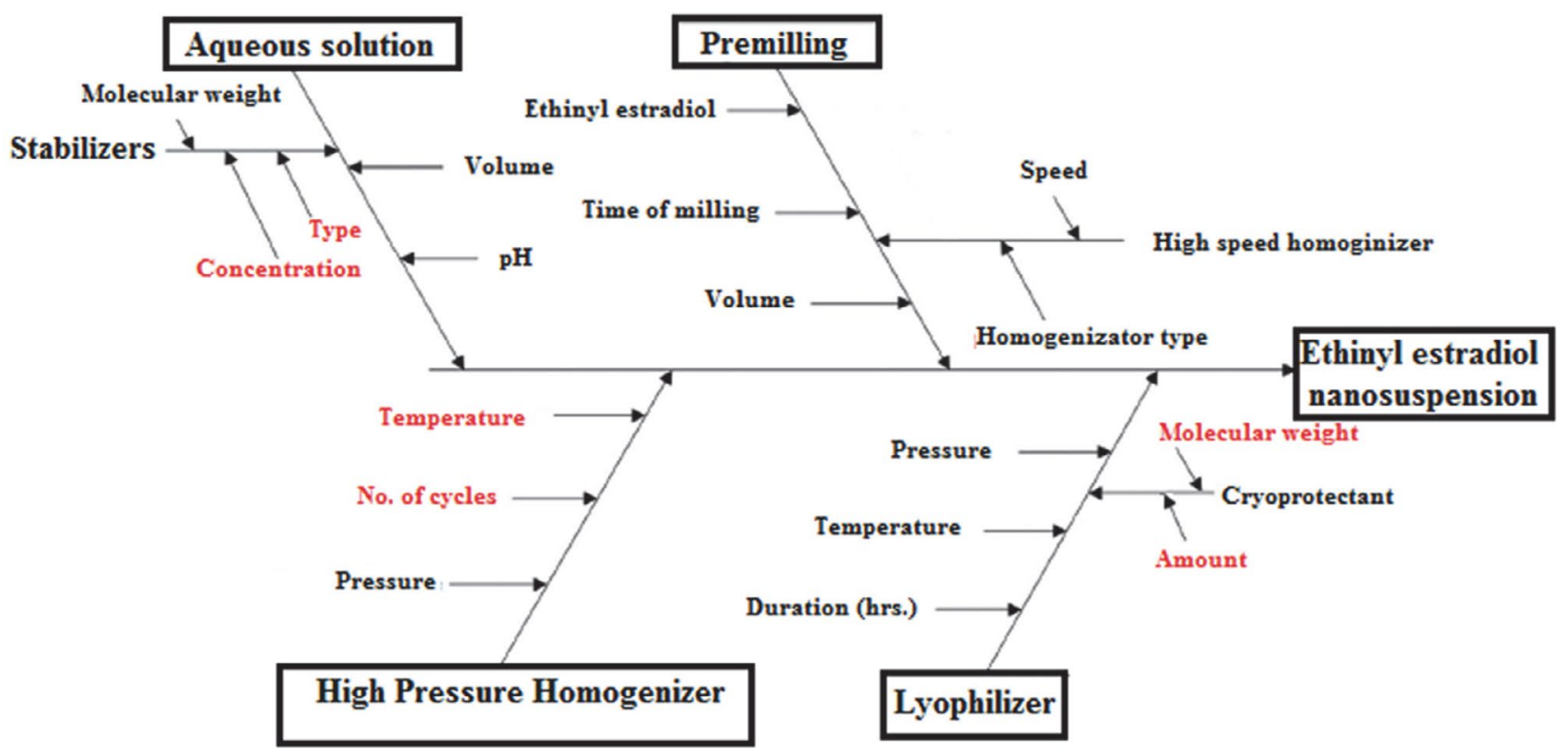

Figure 2. An Ishikawa diagram illustrating process and formulation variables that may influence the properties of NS.

Table 5. Plackett-Burman experimental design matrix with observed values of response variables.

\begin{tabular}{|c|c|c|c|c|c|c|c|c|c|c|c|}
\hline Batch & $\begin{array}{c}\mathrm{X} 1 \\
(\mathrm{rpm})\end{array}$ & $\begin{array}{c}\mathrm{X} 2 \\
(\mathrm{~min} .)\end{array}$ & $\begin{array}{c}\mathrm{X} 3 \\
\left(\text { Bars }^{*} 1000\right)\end{array}$ & $\mathrm{X} 4$ & $\begin{array}{c}\text { X5 } \\
(\mathrm{mg})\end{array}$ & $\begin{array}{c}\text { X6 } \\
(\mathrm{mg})\end{array}$ & $\begin{array}{c}\text { X7 } \\
(\mathbf{m g})\end{array}$ & $\begin{array}{c}\text { X8 } \\
(\mathbf{m g})\end{array}$ & $\begin{array}{l}\mathrm{Y} 1^{*} \\
(\mathrm{~nm})\end{array}$ & $\begin{array}{l}Y 2^{*} \\
(\%)\end{array}$ & $\begin{array}{l}\mathrm{Y3}^{*} \\
(\%)\end{array}$ \\
\hline 01 & 1 & -1 & 1 & 1 & 1 & -1 & -1 & -1 & 221 & 90.67 & 90.57 \\
\hline 02 & -1 & -1 & -1 & -1 & -1 & -1 & -1 & -1 & 324 & 92.78 & 92.46 \\
\hline 03 & -1 & -1 & 1 & -1 & 1 & 1 & -1 & 1 & 234 & 89.99 & 88.16 \\
\hline 04 & -1 & 1 & -1 & 1 & 1 & -1 & 1 & 1 & 351 & 90.01 & 89.62 \\
\hline 05 & 1 & 1 & -1 & 1 & 1 & 1 & -1 & -1 & 230 & 95.89 & 85.61 \\
\hline 06 & -1 & -1 & -1 & 1 & -1 & 1 & 1 & -1 & 316 & 94.78 & 90.61 \\
\hline 07 & -1 & 1 & 1 & 1 & -1 & -1 & -1 & 1 & 298 & 89.19 & 85.09 \\
\hline 08 & -1 & 1 & 1 & -1 & 1 & 1 & 1 & -1 & 313 & 90.67 & 80.91 \\
\hline 09 & 1 & 1 & 1 & -1 & -1 & -1 & 1 & -1 & 309 & 89.45 & 85.88 \\
\hline 10 & 1 & -1 & -1 & -1 & 1 & -1 & 1 & 1 & 278 & 90.11 & 89.95 \\
\hline 11 & 1 & 1 & -1 & -1 & -1 & 1 & -1 & 1 & 298 & 98.76 & 91.7 \\
\hline 12 & 1 & -1 & 1 & 1 & -1 & 1 & 1 & 1 & 322 & 90.56 & 89.09 \\
\hline
\end{tabular}

Table 6. ANOVA analysis for response variables in Plackett - Burman design matrix.

\begin{tabular}{|c|c|c|c|c|c|c|c|c|}
\hline & & & \multicolumn{2}{|c|}{$\begin{array}{c}\text { Y1: Particle size } \\
(\mathbf{n m})\end{array}$} & \multicolumn{2}{|c|}{$\begin{array}{c}\text { Y2: Drug content } \\
\text { (\%) }\end{array}$} & \multicolumn{2}{|c|}{$\begin{array}{c}\text { Y3: Entrapment } \\
\text { efficiency (\%) }\end{array}$} \\
\hline & & & p value & $\%$ Contribution & p value & \% Contribution & p value & $\%$ Contribution \\
\hline$\beta_{0}$ & : & Constant & 0.2454 & - & 0.0767 & - & 0.3613 & - \\
\hline A & : & Speed of homogenizer ${ }^{*}(\mathrm{rpm})$ & 0.1747 & 13.74 & 0.1869 & 5.33 & 0.5725 & 2.41 \\
\hline $\mathrm{B}$ & : & Time of homogenizer ${ }^{* * *}$ (min.) & 0.3769 & 4.69 & 0.3595 & 2.14 & 0.1014 & 33.02 \\
\hline $\mathrm{C}$ & : & Homogenization pressure $^{* *}\left(\operatorname{Bar}^{\star} 1000\right)$ & 0.3931 & 4.34 & 0.0190 & 39.35 & 0.1208 & 27.90 \\
\hline $\mathrm{D}$ & : & Number of cycles & 0.8693 & 0.14 & 0.8974 & 0.036 & 0.8813 & 0.16 \\
\hline $\mathrm{E}$ & : & Concentration of Soya lecithin ${ }^{*}(\mathrm{mg})$ & 0.0969 & 24.97 & 0.1806 & 5.54 & 0.3659 & 6.82 \\
\hline $\mathrm{F}$ & : & Concentration of $\mathrm{SLS}^{* *}(\mathrm{mg})$ & 0.5472 & 2.00 & 0.0296 & 28.16 & 0.4847 & 3.82 \\
\hline G & : & Concentration of Tween $80^{*}(\mathrm{mg})$ & 0.0664 & 34.97 & 0.0888 & 11.33 & 0.4825 & 3.86 \\
\hline $\mathrm{H}$ & : & Concentration of Ethinyl estradiol (mg) & 0.5472 & 2.00 & 0.3183 & 2.62 & 0.4804 & 3.90 \\
\hline
\end{tabular}

${ }^{*}$ Included in the model of particle size; ${ }^{* *}$ Included in the model of drug content; ${ }^{* * *}$ Included in the model of entrapment efficiency. 


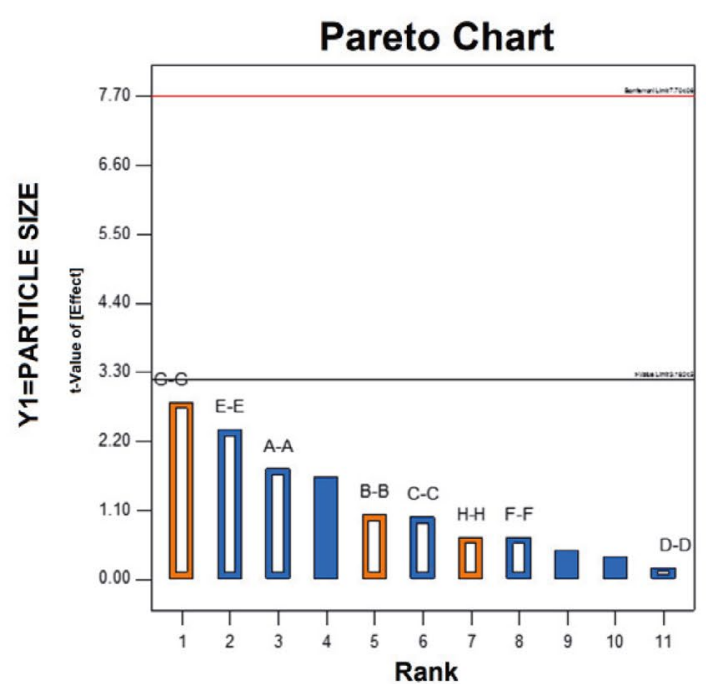

Designexperts Software

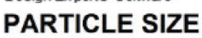

A: Speed of homoginizer(preliminary nanosuspension

C. Homogenization pressure

E: CONC. OF SOYA LECITIN

F: CONC. OF SLS

G: CONC. OF TWEEN 80

H CONC. OF ETHINYL ESTRADIOL

J: J

L: $\mathrm{L}$ ositive Effects

- Positive Effects

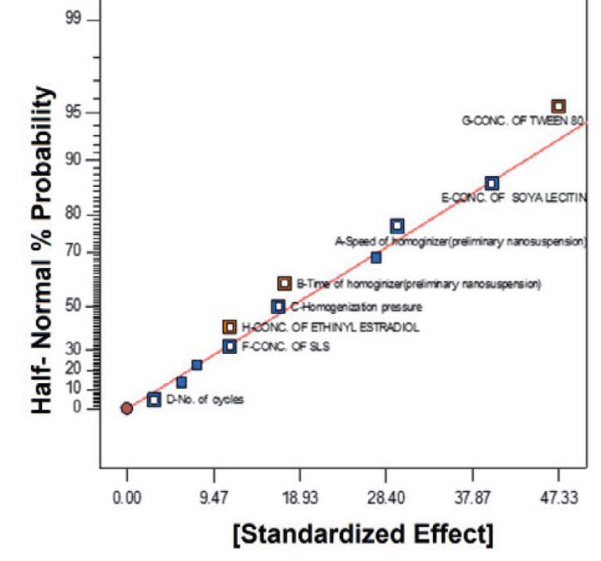

Half- Normal Plot

[Standardized Effect]
Half- Normal Plot DRUG CONTENT

A: Speed of homoginizer(preliminary nanosuspension B: Time of homoginizer(preliminary nanosuspension) C. Homogenization pressure D. No of cycles

E: CONC. OF SOYA LECITIN

$G$ CONC. OF TWEEN 80

G. CONC. OF TWEEN 80

H: CONC:
J: J
K: K

K: K

a Positive Effects

a Negative Effects

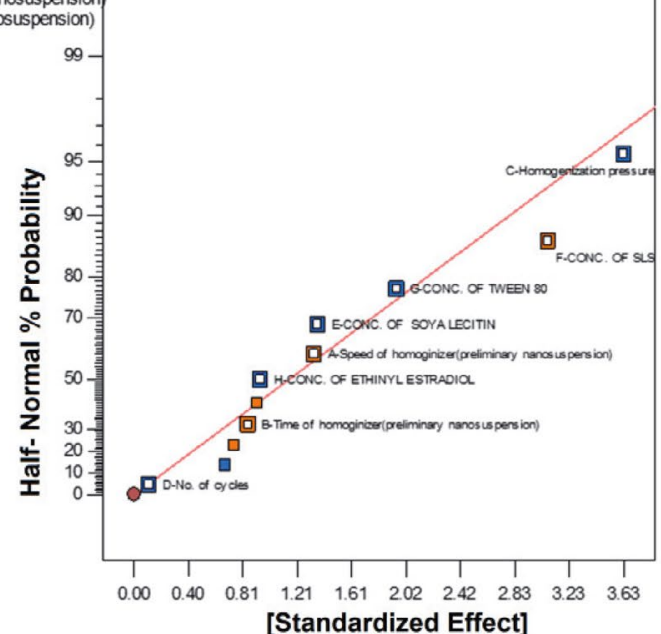

[Standardized Effect]

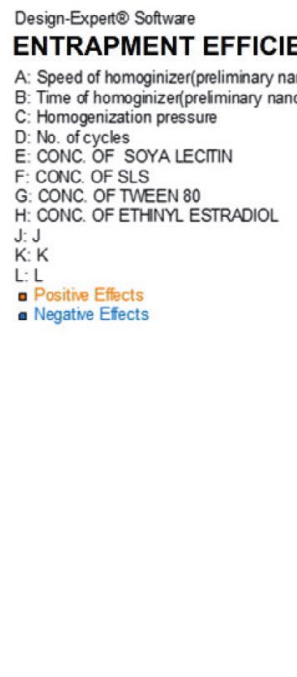

Half- Normal Plot

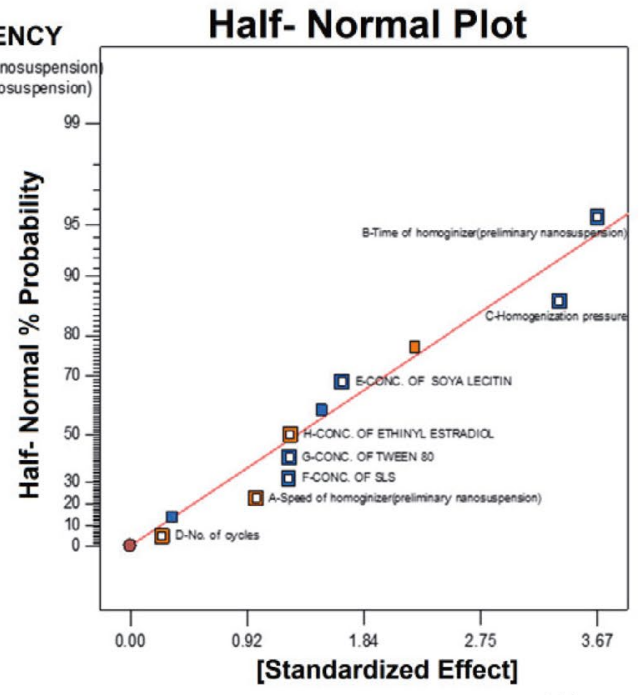

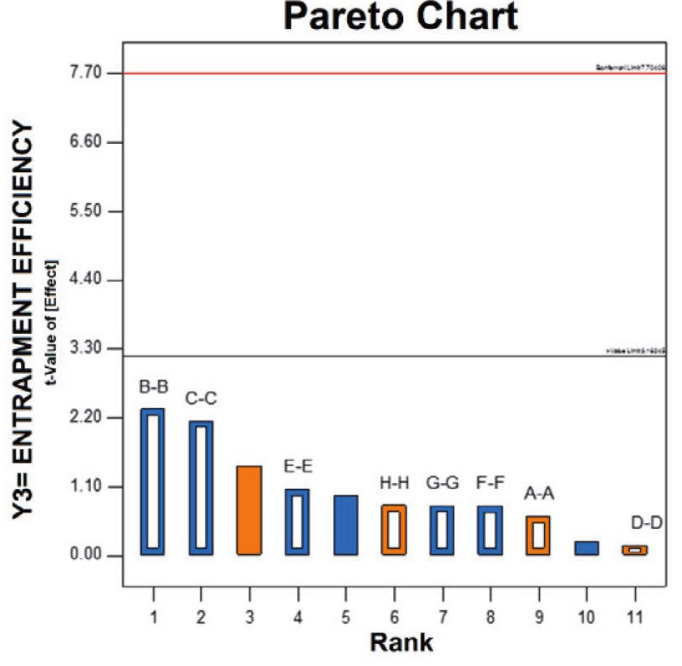

Figure 3. The half-normal plot and Pareto charts showing the significant process and formulation variables on particle size, drug content and entrapment efficiency. 
high-speed homogenizer (X1), respectively (Table 6) (Fig. 3a).

The value of $\mathrm{R}^{2}$ found was 0.8686 , which indicates significant model fitting of the tested model. From ANOVA the $\mathrm{p}$-value for main effects obtained was 0.2454 , which was not statistically significant; hence, by using CCD most significant factors were further evaluated. Particle size plays an important role for EENPs as it influences the physical stability, cellular uptake, drug release, bioavailability and biodistribution of the drugs.

Following polynomial equation can describe Y1,

$$
\begin{aligned}
& \text { Particle size }=+291.17-14.83 * \mathrm{~A}+8.67 * \\
& \mathrm{~B}-8.33 * \mathrm{C}-1.50 * \mathrm{D}-20.00 * \mathrm{E}- \\
& 5.67 * \mathrm{~F}+23.67 * \mathrm{G}+5.67 * \mathrm{H}
\end{aligned}
$$

Polynomial Eq. 2 represents that, upon an increase in the concentration of tween 80 and $\mathrm{EE}$, there is a decrease in average particle size (Y1). It also decreases with decreasing speed of homogenizer in primary NS stage with an increasing number of cycles with higher homogenizer pressure. Thus, from all the process variables, the percentage contribution for average particle size is the concentration of tween 80 (34.97\%), the concentration of SL (24.97\%) and speed of homogenizer (13.74\%), respectively. The smallest particle of $221 \mathrm{~nm}$ could be achieved by using $0.15 \% \mathrm{v} / \mathrm{v}$ of Tween 80 , $30 \mathrm{mg}$ of SL with homogenization speed of $8000 \mathrm{rpm}$.

For the Drug content (Y2), the most contributed and significant factors were the concentration of tween 80
(X7), the concentration of SLS (X6), and homogenization pressure (X3), respectively (Table 6) (Fig. 3b). The $\mathrm{R}^{2}$ value (0.9450) indicate a significant fit to the model being tested. From ANOVA the p-value for main effects obtained was 0.0767 , which was not statistically significant; hence, by using CCD most significant factors were further evaluated. Drug content plays an important role in therapeutic activity at a given dose of EE in NS.

Following polynomial equation can describe Y2,

$$
\begin{aligned}
& \text { Drug content }=+91.91+0.67 * \mathrm{~A}+0.42 \\
& * \mathrm{~B}-1.82 * \mathrm{C}-0.06 * \mathrm{D}-0.69 * \mathrm{E}+1.54 \\
& * \mathrm{~F}-0.98 * \mathrm{G}-0.47 * \mathrm{H}
\end{aligned}
$$

Polynomial Eq. 3 represents that, drug content (Y2) was decreased with increasing concentration of SL, speed of homogenizer in primary NS stage with a decreased time of homogenizer. It also decreases with increasing concentration of tween 80, EE and SLS, followed by increasing pressure and number of cycles of homogenizer, respectively. From all the process variables, the percentage contribution of the concentration of tween $80(11.33 \%)$, the concentration of SL (28.16\%) and homogenizer pressure (39.35\%) influences drug content, respectively. Thus, to achieve $98.76 \%$ of drug content in EENPs, experiments

\begin{tabular}{|c|c|c|c|c|c|c|c|c|c|}
\hline \multirow{3}{*}{ Batch } & \multicolumn{3}{|c|}{ Independent variables } & \multicolumn{6}{|c|}{ Dependent variables } \\
\hline & \multirow[b]{2}{*}{ A (mg) } & \multirow[b]{2}{*}{ B (mg) } & \multirow[b]{2}{*}{ C } & \multicolumn{3}{|c|}{ Observed values } & \multicolumn{3}{|c|}{ Predicted values } \\
\hline & & & & $\mathrm{Y}^{*}(\mathrm{~nm})$ & $\mathrm{Y}^{*}(\%)$ & $\mathrm{Y3}^{*}(\%)$ & Y1 (nm) & Y2 (\%) & Y3 (\%) \\
\hline 01 & 0 & 0 & -1.68179 & 225 & 91.256 & 99.712 & 233.17 & 91.27 & 98.73 \\
\hline 02 & 0 & 0 & 0 & 215 & 87.745 & 99.656 & 219.93 & 87.56 & 99.25 \\
\hline 03 & 0 & 0 & 0 & 204 & 87.235 & 99.665 & 219.93 & 87.56 & 99.25 \\
\hline 04 & -1 & 1 & 1 & 220 & 93.685 & 99.99 & 235.38 & 94.03 & 99.61 \\
\hline 05 & 0 & 0 & 0 & 225 & 87.845 & 99.662 & 219.93 & 87.56 & 99.25 \\
\hline 06 & 1 & -1 & 1 & 192 & 86.231 & 98.5862 & 217.90 & 87.43 & 98.66 \\
\hline 07 & 0 & 0 & 1.68179 & 228 & 89.7962 & 99.764 & 222.35 & 89.55 & 99.77 \\
\hline 08 & 1.68179 & 0 & 0 & 302 & 92.569 & 99.436 & 280.83 & 92.45 & 99.11 \\
\hline 09 & 0 & -1.68179 & 0 & 229 & 89.321 & 99.735 & 240.18 & 88.19 & 98.80 \\
\hline 10 & -1.68179 & 0 & 0 & 225 & 90.89 & 99.567 & 248.69 & 90.77 & 99.39 \\
\hline 11 & -1 & -1 & -1 & 235 & 90.6055 & 98.263 & 236.23 & 91.69 & 98.69 \\
\hline 12 & 1 & -1 & -1 & 278 & 95.4605 & 96.675 & 260.84 & 95.29 & 98.28 \\
\hline 13 & -1 & 1 & -1 & 233 & 89.236 & 97.6064 & 205.32 & 88.21 & 98.75 \\
\hline 14 & 0 & 0 & 0 & 226 & 87.015 & 99.669 & 219.93 & 87.56 & 99.25 \\
\hline 15 & 1 & 1 & -1 & 265 & 88.4011 & 99.947 & 293.43 & 88.64 & 100.04 \\
\hline 16 & 0 & 0 & -1.68179 & 225 & 91.256 & 99.712 & 219.93 & 87.56 & 99.25 \\
\hline 17 & 0 & 0 & 0 & 215 & 87.745 & 99.656 & 219.93 & 87.56 & 99.25 \\
\hline 18 & 0 & 0 & 0 & 204 & 87.235 & 99.665 & 240.34 & 89.46 & 99.70 \\
\hline 19 & -1 & 1 & 1 & 220 & 93.685 & 99.99 & 248.99 & 92.42 & 99.68 \\
\hline 20 & 0 & 0 & 0 & 225 & 87.845 & 99.662 & 267.79 & 85.87 & 100.29 \\
\hline
\end{tabular}
can be performed by using $0.15 \%(\mathrm{v} / \mathrm{v})$ of Tween 80,15 $\mathrm{mg}$ of SL with homogenization pressure of 25000 Bars.

For the Entrapment efficiency (Y3), the most contributed and significant factors were the concentration of

Table 7. Central composite design matrix with observed and predicted values of responses.

${ }^{*} \mathrm{Y} 1=$ Particle size; ${ }^{*} \mathrm{Y} 2$ = Drug content; ${ }^{*} \mathrm{Y} 3$ = Entrapment efficiency. 
Table 8. Results of Quadratic and 2FI model for regression analysis of response variables Y1, Y2 and Y3.

\begin{tabular}{cccccc}
\hline Quadratic model & $\mathbf{R}^{\mathbf{2}}$ & Adjusted $\mathbf{R}^{\mathbf{2}}$ & ${\text { Predicted } \mathbf{R}^{\mathbf{2}}}$ & SD & $\mathbf{\% C V}$ \\
\hline Y1 & 0.6546 & 0.3437 & -1.7414 & 23.28 & 9.80 \\
Y2 & 0.9429 & 0.8915 & 0.5597 & 0.8701 & 0.9719 \\
2FI & $\mathbf{R}^{2}$ & Adjusted $\mathbf{R}^{2}$ & Predicted $\mathbf{R}^{2}$ & SD & $\mathbf{\% C V}$ \\
Y3 & 0.3462 & 0.0444 & -2.8153 & 0.8396 & 0.8460 \\
\hline
\end{tabular}

SL (X5), time of homogenizer (X2), and homogenization pressure (X3), respectively (Table 6) (Fig. 3c). The $\mathrm{R}^{2}$ value (0.8189) indicating a significant fit to the model being tested. From ANOVA the p-value for main effects was found to be 0.3613 , which was not statistically significant; hence, by using CCD most significant factors were further evaluated. Entrapment efficiency plays an important role for entrapment of EE in stabilizer vesicles to stabilize NPs.

Following polynomial equation can describe $\mathrm{Y} 3$,

$$
\begin{aligned}
& \text { Entrapment efficiency }=+88.30+0.50 \\
& * \mathrm{~A}-1.84 * \mathrm{~B}-1.69 * \mathrm{C}+0.13 * \mathrm{D}-0.84 \\
& * \mathrm{E}-0.62 * \mathrm{~F}-0.63 * \mathrm{G}+0.63 * \mathrm{H}
\end{aligned}
$$

Polynomial Eq. 4 represents that, entrapment efficiency (Y3) was decreased with increasing concentration of EE, with increased time of homogenizer and number of cycles of homogenization. It also decreases with increasing concentration of tween 80 , SL and SLS, followed by increasing pressure of homogenizer and speed of homogenizer, respectively. From all the process variables, the percentage contribution of the concentration of SL (6.82\%), time of homogenizer $(33.02 \%)$ and homogenizer pressure (27.90\%) influences entrapment efficiency, respectively. Thus, to achieve $92.46 \%$ of entrapment efficiency in EENPs, experiments can be performed by using $30 \mathrm{~min}$. of homogenization; $15 \mathrm{mg}$ of SL with homogenization pressure of 5000 Bars.

\section{3. 3. Optimization of EENPs by Central Composite Design}

\section{3. 3. 1. Model Fitting}

By design of expert (DOE), 20 runs were proposed and the input of predicted and observed values for Y1, Y2, and Y3 responses ranges from 192-302 nm, 86.23 to $95.46 \%$ and 99.16 to $99.99 \%$ respectively (Table 7 ). The obtained responses were simultaneously fitted to cubic, $2 \mathrm{FI}$, quadratic and linear models. As the $\mathrm{R}^{2}$ values were found to be greater than 0.9 , and both the observed and predicted values were less comparable with standard deviations (SD) $(<1.0 \%)$ and values of precision, thus the best-fitted model for Y1 and Y2 was quadratic and 2FI for Y3. For each response, inputs for linear model parameters are reported in Table 8 . As the ratios of maximum to minimum responses values were less than 10 , transformation is not necessary $(\mathrm{Y} 1=2.51 ; \mathrm{Y} 2=8.17 ; \mathrm{Y} 3=1.17) .{ }^{38}$

\section{3. 3. 2. Analysis of Response Surface Plots}

To study the interaction effects of factors on their responses and relationships, response surface plots were used and were constructed for three responses viz., Y1, Y2, and Y3 (Fig. 4 a, b, c).

\section{Effect on particle size (Y1)}

The proposed polynomial equation for particle size is as follows,

$$
\begin{gathered}
\mathrm{Y} 1=+219.93+9.56(\mathrm{~A})+0.0466 \\
(\mathrm{~B})-3.22(\mathrm{C})
\end{gathered}
$$

where, $\mathrm{Y} 1$ is particle size, (A) concentration of tween 80 , (B) concentration of SL, (C) number of cycles for EENPs formulation by $\mathrm{HPH}$.

The models were found to be significant as the $\mathrm{F}$ value was $<0.002$, while model terms were significant as the Prob $>\mathrm{F}$, the p-value is $<0.0500$, hence these model are used to develop the design space. The $3 \mathrm{D}$ response surface plots were used to study the impact of independent variables on the particle size (Y1). The predicted values of Y1 response ranges from 205.32 to $293.42 \mathrm{~nm}$. The positive value of coefficient represents increasing Y1. Fig. 4 a, predicts that as the concentration of tween $80(\mathrm{~A})$ increases from 0.10 to $0.30(\% \mathrm{v} / \mathrm{v})$, the particle starts to aggregate. This may be due to saturation of surfactant in NS, as formed particles are adsorbed by an excess concentration of surfactant. When the concentration of SL (B) increases from 10 to $30 \mathrm{mg}$ respectively, it fails to prohibit reaggregation of dispersed particles leading to the presence of larger bodies in NS thus increased particle size. Hence increased concentration of surfactant and polymer increases the particle size. The number of cycles (C) for HPH shows a direct relationship with particle size: with an increase in the number of cycles of HPH implies a decrease in the particle size. The coefficient with negative value represents decreasing particle size. Increase in the number of cycles leads to particle size reduction by increasing the viscosity of the system, which inhibits the Ostwald ripening. Hence, an increase in no. of cycles leads to an increase in the dynamic pressure with a decrease in the static pressure at room temperature (RT), below the boiling point of water. Hence, water in the system boils at RT by forming the gas bubbles that implode, when the pressure of the system is reached to normal after leaving of 


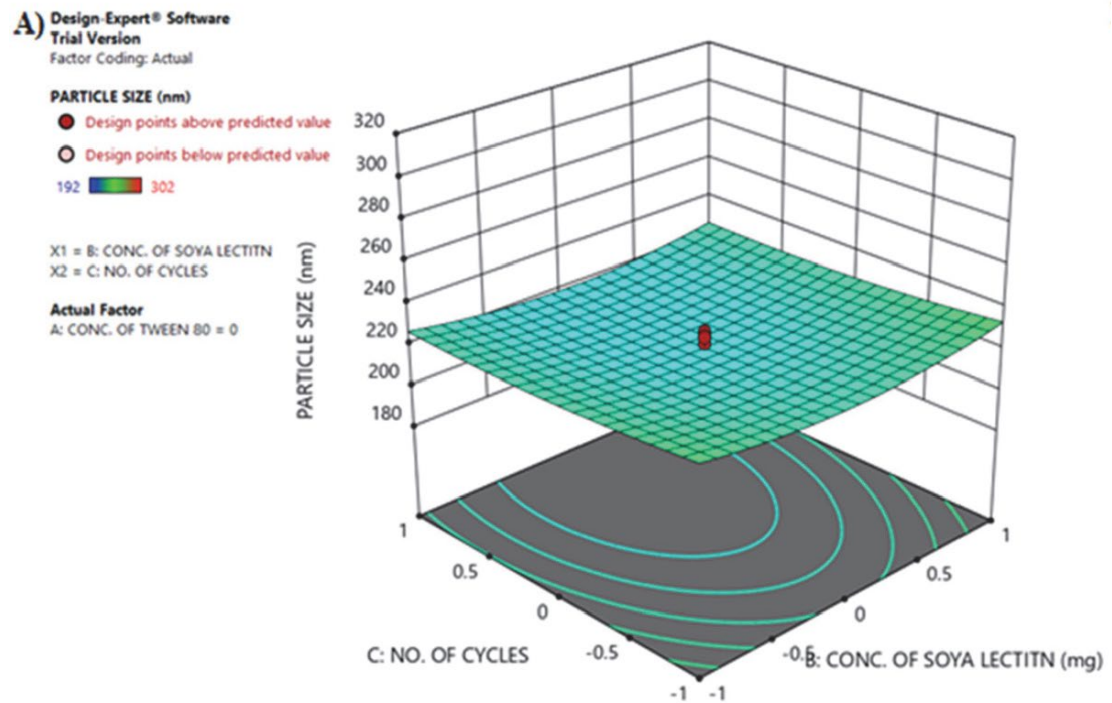

B) Design Expert software
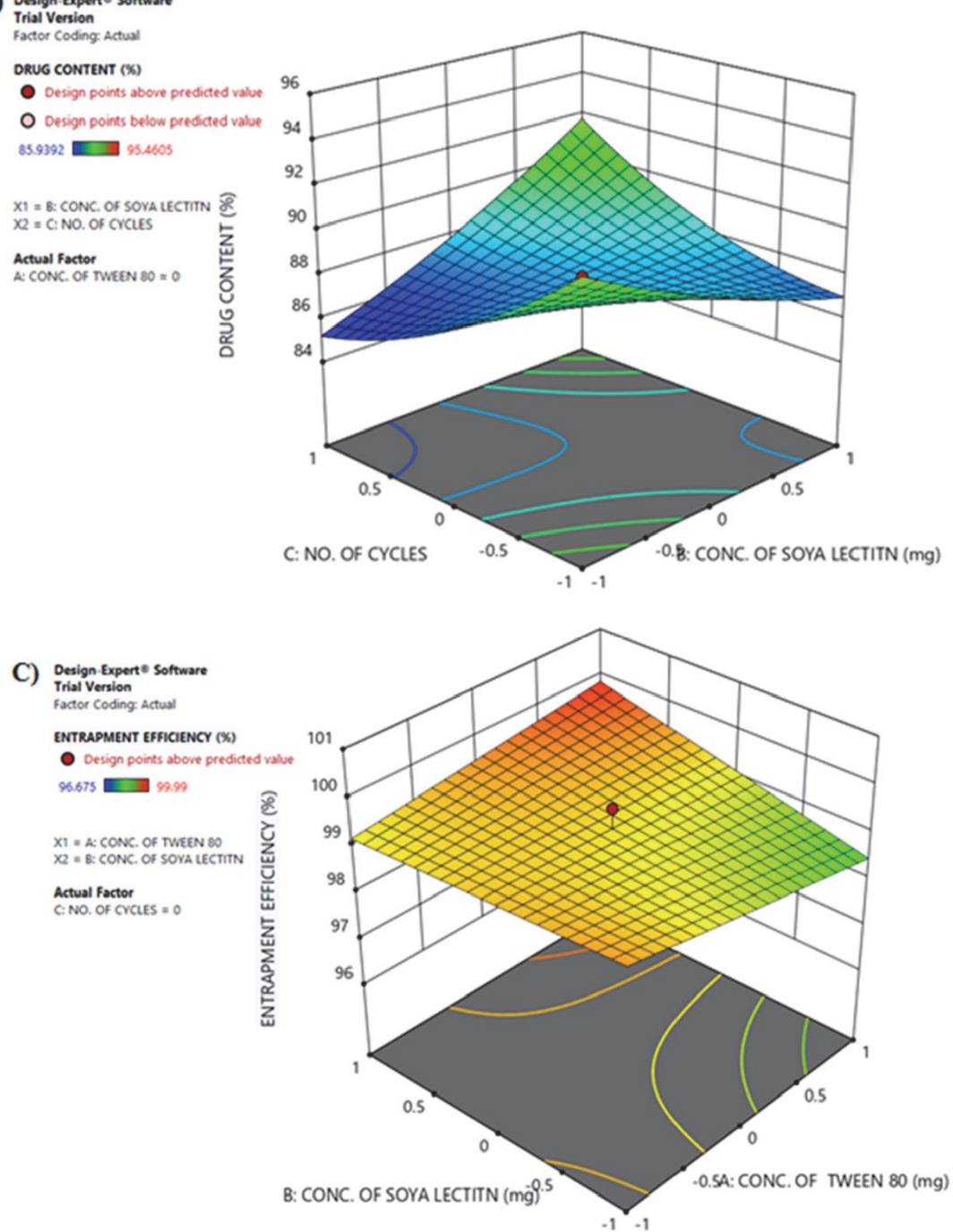

Figure 4. 3D surface response plot showing: a) The effect of factor C (number of cycles) and factor B (concentration of soya lecithin) on response Y1 (particle size).

B) The effect of factor C (number of cycles) and factor B (concentration of soya lecithin) on response Y2 (drug content).

C) The effect of factor B (concentration of soya lecithin) and factor A (concentration of tween 80 ) on response Y2 (drug content). 
NS from the gap. This is the reason for particle size reduction.

\section{Effect on drug content (Y2)}

The proposed polynomial equation for drug content is as follows,

$$
\mathrm{Y} 2=+87.56+0.50(\mathrm{~A})+0.38(\mathrm{~B})-0.51(\mathrm{C})
$$

The predicted Y2 response values range from 85.87 to $95.29 \%$. The models were found to be significant as the $F$ value were $<0.0001$, while model terms were significant as the Prob $>F$, the $p$-value is $<0.0500$, hence these model were used to develop the design space. Here the significant model term is ' $\mathrm{A}$ ' as an increase in the amount of ' $\mathrm{A}$ ' leads to an increase in drug content. While the concentration of SL 'B' shows the negligible effect on drug content (Fig. 4 b). The drug content also decreases with an increasing number of cycles ' $\mathrm{C}$.' However, drug content had the most important effect on drug dissolution, which directly affects the absorption of the drug and thus bioavailability.

\section{Effect on entrapment efficiency (Y3)}

The proposed polynomial equation for entrapment efficiency is as follows,

$$
\mathrm{Y} 3=+99.25-0.08(\mathrm{~A})+0.27(\mathrm{~B})+0.31(\mathrm{C})
$$

The predicted values of Y 3 are shown in Table 6 and ranges from $96.68-99.99 \%$. The model was found to be significant as F-value was $<0.0001$. Here, in this model 'B' $\&$ ' $\mathrm{C}$ ' terms are significant. The 3D surface response plots are shown in Fig. $4 \mathrm{c}$ predicts that the $\%$ entrapment efficiency increases with an increase in values of 'B' \& 'C'. This may be due to significant interaction of SL with $\mathrm{EE}$ in NS. Optimum entrapment efficiencies allow control release of EE from NS. Entrapment efficiency increases the drug loading capacity of NS with increased dosing intervals, less toxicity due to the excipients and residual solvents, and more appropriate dosing. Thus, the factors i.e. concentration of SL and number of homogenization cycles that affects entrapment efficiency was optimized by CCD.

Table 9. Residual values of CQAs of optimized formulations.

\section{3. 4. Optimization Model Validation}

To achieve the predicted (software suggestions) composition, targeted criteria were fed into the software. The software-suggested values were selected as a region of interest based on desirability values and were practically used for their verification. The design expert software was used to statistically validate the obtained polynomials by ANOVA.

For the construction of design space graphical method was selected for this study. The desirability values based on selected software suggestion were found to be 0.922 , which provides an assurance of $92.20 \%$ possibilities to achieve the target with optimized CMAs and CPPs. This indicates higher the value of desirability, more is the possibility to achieve the target. ${ }^{30}$

The final formulation was prepared with optimized CMAs and CPPs, and its CQAs were analyzed. The actual results and predicted results of CQAs were further used to calculate the residual values to ensure the achievement of design space. The calculation of residual values is also a verification/validation of the model and CQAs. The residual values were calculated as percent residual using the following formula:

Percent residual

$$
=\frac{\text { Software suggested results }- \text { Actual obtained results }}{\text { Software suggested results }} \times 100
$$

The optimized CMAs and CPPs with residual values of CQAs are summarized in Table 9.

The residual values were found to be very low ( between the range of -1.15 and 0.240 ) which shows that the obtained results have a very strong correlation with software predicted results. Lower residual value is also an indicator of less variation and more reproducibility of CQAs with the optimized CMAs and CPPs. ${ }^{30}$ The effect of two independent variables i.e. concentration of SL and no. of cycles of HPH are found to be more predominant from DOE results. The concentration of tween 80 favors the entrapment efficiency of EENPs, thus to enhance the adaptability of the method, the concentration of tween 80 was fixed to $0.15 \%(\mathrm{v} / \mathrm{v})$ and by using remaining two factors the design space was developed. The overlay plot obtained from DOE software (Fig. 5) shows the design space to select an optimum concentration of SL and no. of cycles to

\begin{tabular}{lcccccc}
\hline Response parameters & $\begin{array}{c}\text { CMAs/CPPs } \\
\text { lecithin } \mathbf{( m g )}\end{array}$ & $\begin{array}{c}\text { No. of } \\
\text { cycles }\end{array}$ & $\begin{array}{c}\text { Conc. of Tween } \\
\mathbf{8 0} \mathbf{( \% ~ v / v )}\end{array}$ & $\begin{array}{c}\text { Particle size } \\
(\mathbf{n m})\end{array}$ & $\begin{array}{c}\text { CQAs } \\
\text { Drug content } \\
\text { (\%) }\end{array}$ & $\begin{array}{c}\text { Entrapment } \\
\text { efficiency (\%) }\end{array}$ \\
\hline Software-predicted results & 20.68 & 31 & 0.15 & 246.036 & 89.411 & 99.36 \\
Actual obtained results & 21 & 31 & 0.15 & $220 \pm 0.37$ & $92.23 \pm 0.45$ & $99.52 \pm 0.52$ \\
Residual values (\%) & - & - & - & -1.15 & 0.223 & 0.240 \\
\hline
\end{tabular}

${ }^{*} \mathrm{CMAs}=$ critical material attributes; $\mathrm{CPPs}=$ critical processing parameters; $\mathrm{CQAs}=$ critical quality attributes. 
Table 10. Results of optimized batches obtained from an overlay plot of design expert software.

\begin{tabular}{|c|c|c|c|c|c|c|c|c|c|}
\hline \multirow[t]{2}{*}{$\begin{array}{l}\text { Optimized } \\
\text { batch }\end{array}$} & \multicolumn{3}{|c|}{$\begin{array}{l}\text { Independent } \\
\text { variables }\end{array}$} & & \multicolumn{5}{|c|}{ Dependent variables } \\
\hline & A & $\mathrm{B}$ & $\mathrm{C}$ & $\mathrm{Y} 1$ & Y2 & $\mathrm{Y} 3$ & Y1 & $\mathrm{Y} 2$ & Y3 \\
\hline CCD 21 & 19.10 & 28 & 0.15 & $222 \pm 0.25$ & $89.52 \pm 0.55$ & $99.01 \pm 0.45$ & 223.553 & 88.223 & 98.66 \\
\hline CCD 22 & 19.08 & 29 & 0.15 & $253 \pm 0.31$ & $91.41 \pm 0.54$ & $98.68 \pm 0.48$ & 255.41 & 93.785 & 98.41 \\
\hline CCD 23 & 20.68 & 31 & 0.15 & $220 \pm 0.37$ & $92.23 \pm 0.45$ & $99.52 \pm 0.52$ & 246.036 & 89.411 & 99.36 \\
\hline
\end{tabular}

${ }^{*} \mathrm{~A}=$ Concentration of Soya lecithin (mg); B = Number of Cycles; C = Concentration of Tween 80 \% (v/v); Y1 = Particle size (nm); Y2 = Drug Content (\%); Y3 = Entrapment efficiency (\%).

prepare highly stable NS with lesser particle size. The three points that are located in the design space predicts good responses. By changing the composition of factors ' $\mathrm{A}$ ' and ' $\mathrm{B}$ ' as per design space and keeping the concentration of tween $80 \mathrm{fix}$, three formulations, CCD21, CCD22, CCD23 were developed and then characterized for three dependent variables. The plots constructed between predicted and observed responses showed good correlation between the observed (actual) values and theoretical (predicted) values for Y1 (particle size), Y2 (drug content) and Y3 (entrapment efficiency) responses (Table 10 and Figs. 6 $\mathrm{a}, \mathrm{b}, \mathrm{c})$.
Negligible changes were seen in drug content, entrapment efficiency and particle size of CCD21, CCD22, and CCD23 as compared to above formulations. The CCD23 was selected as optimized EENPs formulation based on the data obtained from the three responses. The optimized formulation showed the particle size of $220 \pm$ $0.37 \mathrm{~nm}$ which indicates that cellular uptake of the prepared formulation may be good, as cellular uptake depends upon particle size. Entrapment efficiency is $99.52 \pm$ $0.52 \%$ that confirms increases drug loading capacity of NS with increased dosing intervals, less toxicity due to the excipients and residual solvents. The drug content values
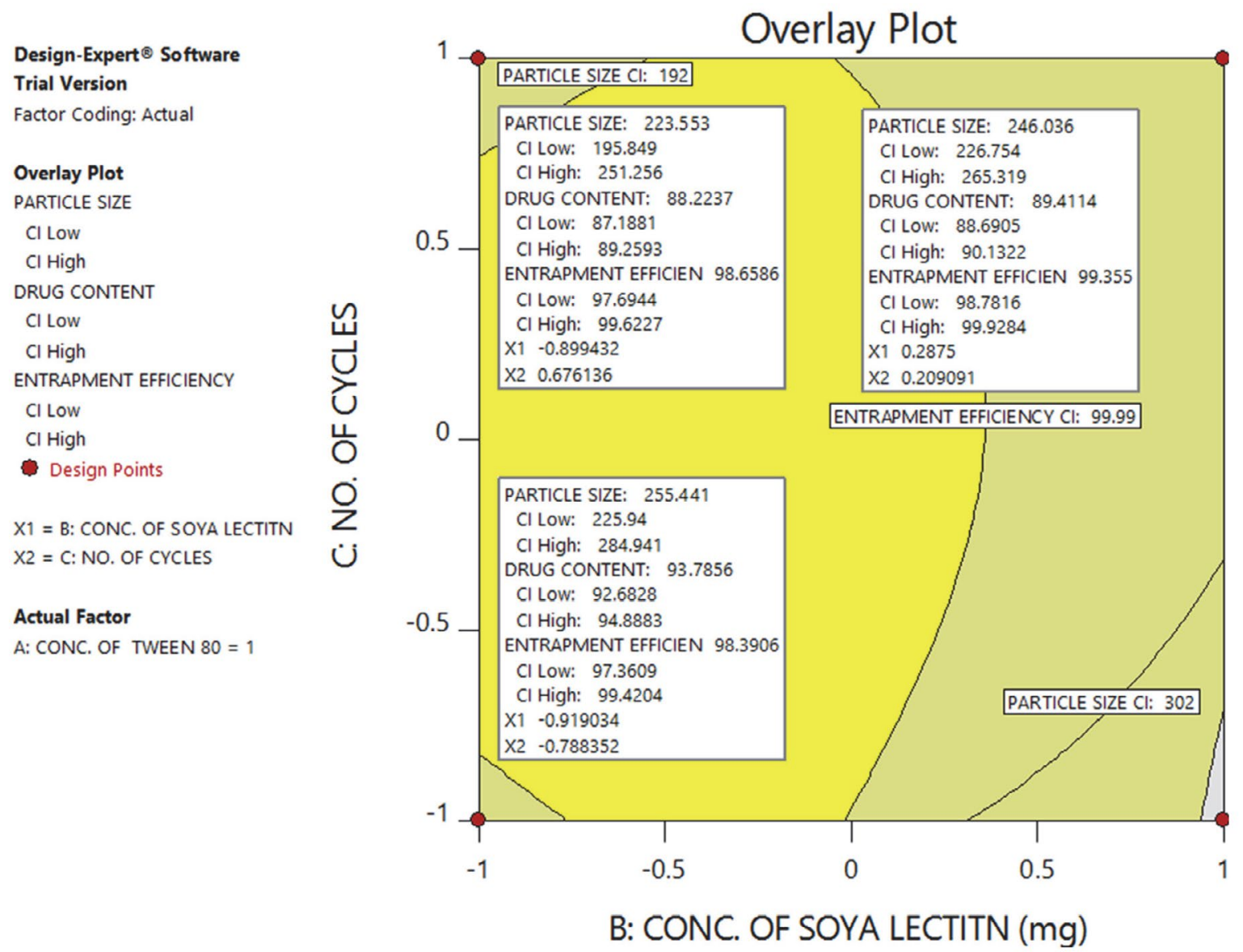

Figure 5. Overlay plot proposed by the design expert software showing design space in yellow colour along with the compositions of selected optimized formulations with the responses. 


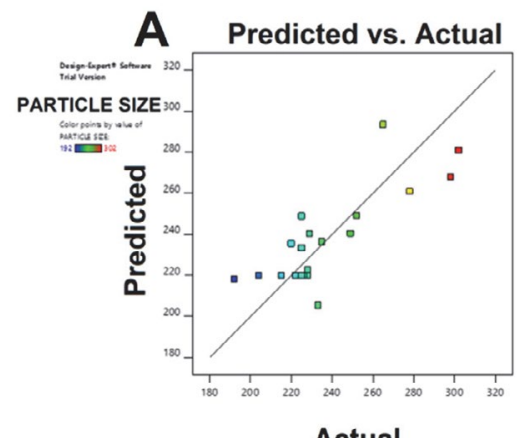

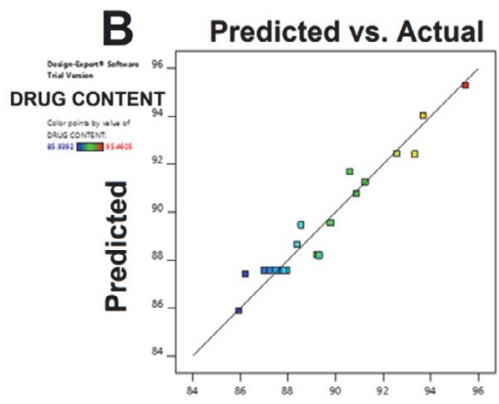

Actual

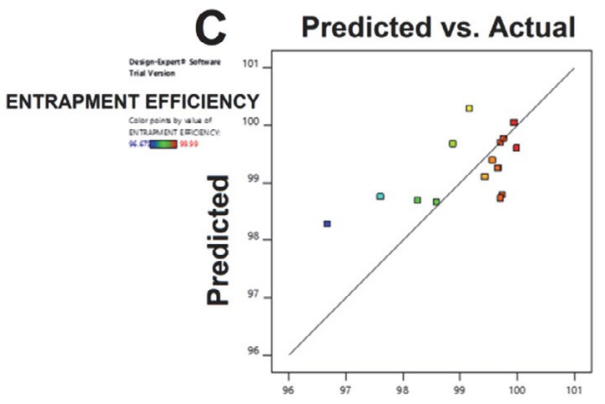

Actual

Figure 6. Liner correlation plots between actual and predicted values of responses: a) particle size (nm), B) drug content (\%), C) entrapment efficiency $(\%)$.

were found to be $92.23 \pm 0.45 \%$ which has the most important effect on drug dissolution, which directly affects the absorption of the drug and thus bioavailability. Further, they were dried using lyophilizer with $6 \%$ of mannitol as a cryoprotectant to stabilize the system.

\section{4. Particle Size Analysis, Polydispersity Index and Particle Charge (Zeta-potential)}

$\mathrm{EE}$ is a coarse micronized powder with fine white texture, poor flow properties, and aqueous solubility. The coarse EE particles bear average particle size of 5-7 $\mu \mathrm{m}$, with 8.38 PDI indicating broad size distribution. The freshly prepared NS was lyophilized to enhance its stability. The lyophilized EENPs powder was smooth in appearance with the particle size $220 \pm 0.37 \mathrm{~nm}$ (Fig. 7 a), which was easily re-dispersed upon gentle shaking. It has been reported that narrow and uniform particle size distribution favors dissolution enhancement, boosts intestinal absorption and improves oral bioavailability. ${ }^{36}$ Optimized EENPs showed PDI value equal to $0.22 \pm 0.15$ indicating the narrow distribution of particles and thus better stability of NS.

Another important significant index is zeta potential, which directly affects the stability of the dispersion system, as it reflects steric or electrostatic barriers preventing aggregation and agglomeration of nanoparticles. When drug particles possess very low values of zeta potential to provide sufficient steric or electric repulsion between each other, aggregation of particles is likely to occur. Generally, for electrostatically stabilized systems maximum $-30 \mathrm{mV}$ of zeta potential or sterically stabilized formulation system at least $-20 \mathrm{mV}$ was sufficient for physical stabilization of NS (Fig. 7 b). The zeta potential of reconstituted EENPs was $-19.3 \pm 6.73 \mathrm{mV}$ indicating physical stability of the optimized NS. ${ }^{36}$

\section{5. Scanning Electron Microscopy (SEM)}

The coarse EE particles bear's average particle size of 5-7 $\mu \mathrm{m}$ with broad size distribution observed (Fig. 8a) in SEM. The SEM (Fig. 8b) of optimized lyophilized EENPs shows that particles were discrete with an absence of agglomeration that may be assigned by the existence of stabilizer.

They had a porous surface and found to be slightly elongated and needle in shape. These pores may be developed due to evaporation of the solvent system from the surface of EENPs during lyophilization. Thus SEM pictures confirm that the larger scaly particles of EE were successfully converted to nearly elongated, smaller sized

\section{A) Size Distribution by Intensity}

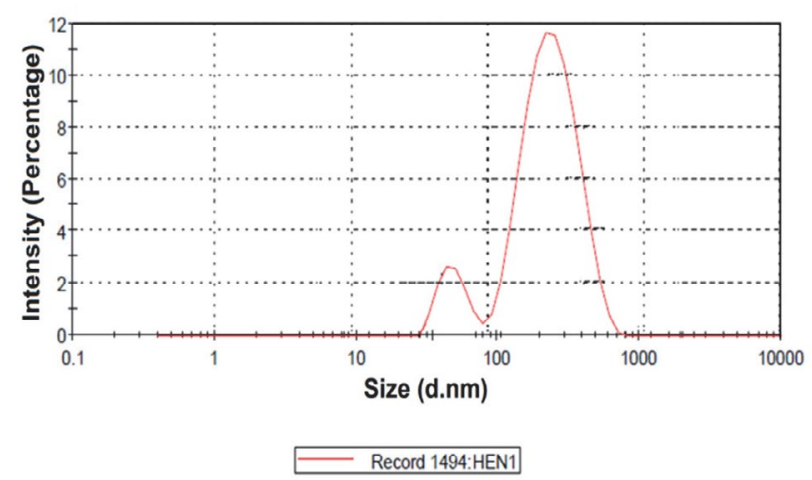

Figure 7. Graph showing: a) average particle size, b) zeta potential.

\section{B) Zeta Potential Distribution}

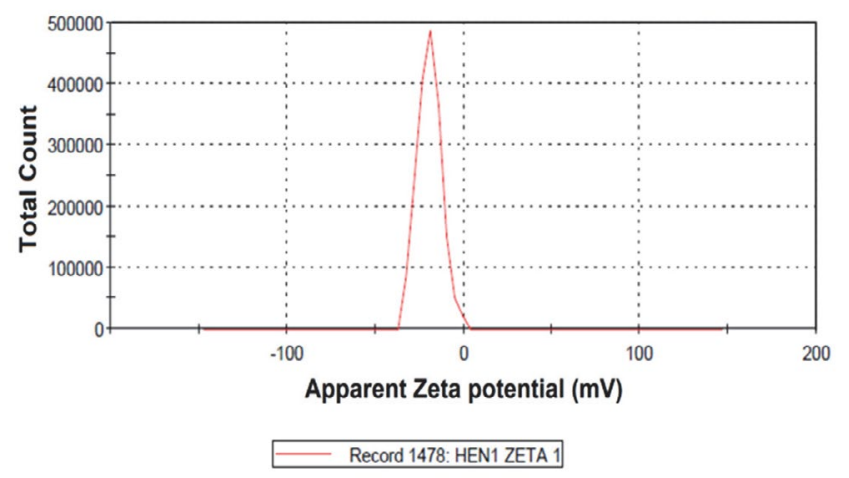



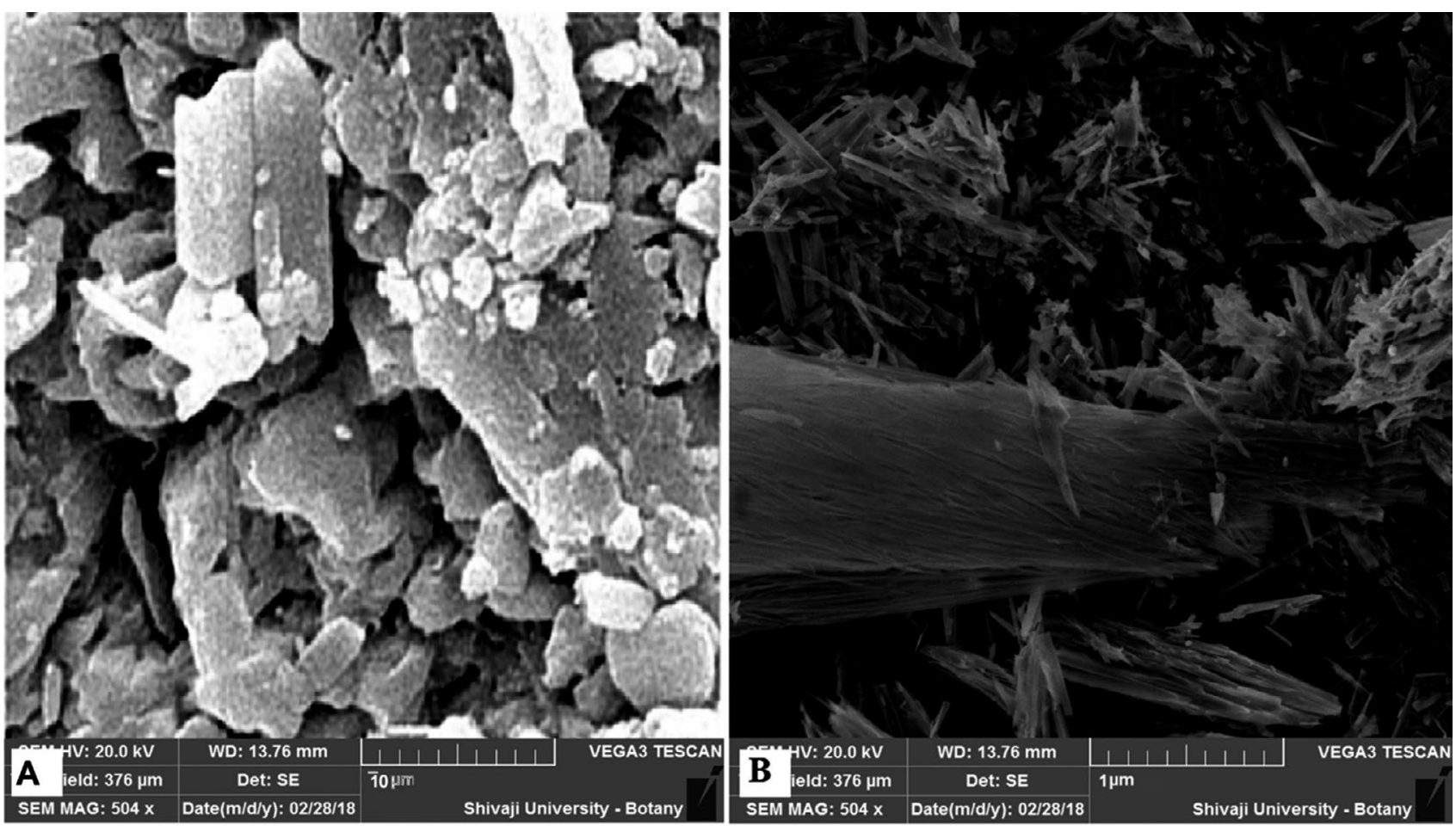

Figure 8. a) SEM images of pure ethinyl estradiol, (b) optimized nanosuspension (EENPs).

nanoparticles with a smoother surface on size reduction. The particle size of EENPs was increased in lesser extent but smaller than EE, after lyophilization. ${ }^{34}$

\section{6. Saturation Solubility Studies}

Saturation solubility studies were carried out for pure drug EE and optimized lyophilized EENPs in double-distilled water. The saturation solubility of EENPs was $805.84 \pm$ $0.05 \mu \mathrm{g} / \mathrm{mL}$ and coarse EE powder was $165.61 \pm 0.02 \mu \mathrm{g} / \mathrm{ml}$. Here the saturation solubility of EE in NS form is increased by 4.86 folds over pure EE. This is because of decreased particle size and increased surface area of EENPs as compared to pure drug. Ostwald Freundlich equation states that decreasing particle size increases saturation solubility (Cs)

$$
\log \frac{C s}{C}=\frac{2 s V}{2.303 R T r 1 r}
$$

where, $\mathrm{s}=$ interfacial tension substance, $\mathrm{C}=$ solubility of the solid consisting of large particles, $\mathrm{R}=$ gas constant, $\mathrm{r}_{1}=$ density of the solid, $\mathrm{Cs}=$ solubility, $\mathrm{r}=$ radius, $\mathrm{V}=$ molar volume of the particle material, and $\mathrm{T}=$ absolute temperature.

Another reason that increases saturation solubility is explained by the Kelvin equation, which suggests that dissolution pressure increases with increasing curvature that occurs with decreasing particle size. When the particle size is reduced to the nanometre range, the curvatures formed are enormous. ${ }^{39}$

\section{7. Fourier Transform Infrared Spectroscopy (FTIR)}

The FTIR spectra of EE coarse powder, physical mixture (PM), and optimized lyophilized EENPs are justified in Fig. 9. The FTIR spectra of EE coarse powder revealed characteristic peaks at 3369.546 and $3288.872 \mathrm{~cm}^{-1}$ which is attributed to intermolecular polymeric $\mathrm{OH}$ bonding, $2974.151 \mathrm{~cm}^{-1}$ peaks is indicating to $\mathrm{C}-\mathrm{H}$ stretching of $\mathrm{CH}_{3}$-CO- group, 2921.704 and 2853.140 revealed to $\mathrm{C}-\mathrm{H}$ stretching of $>\mathrm{CH}_{2}$ group, while 1584.659 is attributed to acids i.e. $\mathrm{C}=\mathrm{O}$ stretching.

The characteristic peak at $1356.175 \mathrm{~cm}^{-1}, 1283.928$ $\mathrm{cm}^{-1}$ and $1058.227 \mathrm{~cm}^{-1}$ are attributed to $\mathrm{C}-\mathrm{H}$ deformation of $-\mathrm{CH}_{2}-\mathrm{CO}$ - group, $\mathrm{C}-\mathrm{O}$ stretching and $\mathrm{O}-\mathrm{H}$ deformation (in-plane) of a secondary alcohol, and C-O stretchings of aralkyl respectively. The FTIR spectra of EENPs shows broadening of peaks at $3269.073 \mathrm{~cm}^{-1}$ of OH bonding and C-H stretching at $2935.012 \mathrm{~cm}^{-1}$ which could be due to diluting effect of mannitol or may be due to the formation of a hydrogen bond between the N-H group of soya lecithin with the carbonyl group of EE. An extra peak was observed in EENPs at $1732.708 \mathrm{~cm}^{-1}$ is the characteristic peak of Tween 80. Absence of characteristics peaks of EE at $2974.151 \mathrm{~cm}^{-1}, 2921.704$ and $2853.140 \mathrm{~cm}^{-1}$ in EENPs may be due to overlapping peaks of tween 80 and soya lecithin. Furthermore, the shifting of peaks to its lower wave number and broadening of characteristic peaks of EE which is seen in EENPs may be due to intermolecular hydrogen bonding, while in PM all characteristic peaks of 


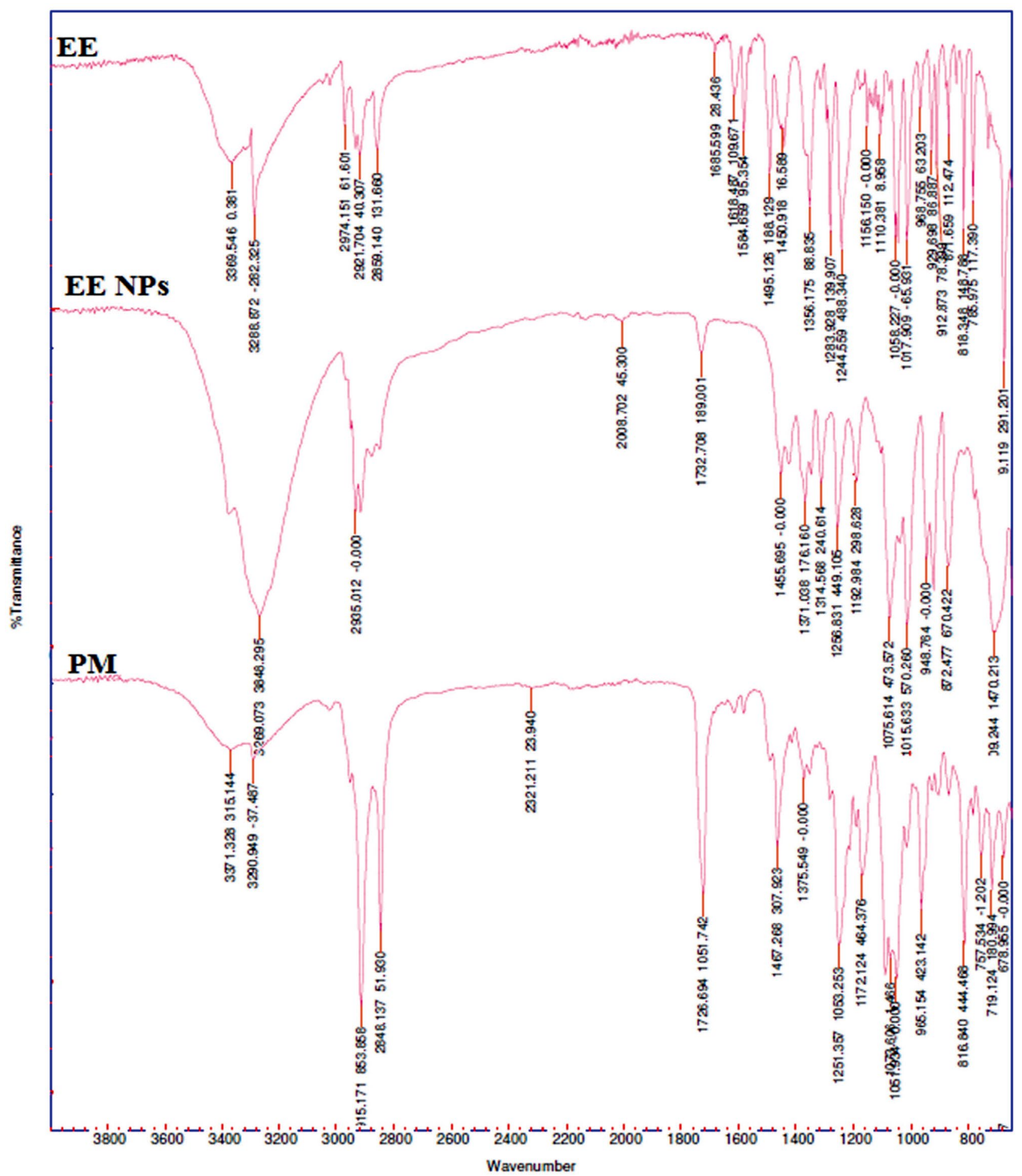

Figure 9. FTIR spectrum of: a) pure ethinyl estradiol, b) optimized nanosuspension (EENPS), c) physical mixture.

EE were retained with the slight shifting of wavenumber. Thus, there may be physical interactions occurring between functional groups of the drug and excipients, probably by the formation of a weak hydrogen bond. The physical interactions found here could be beneficial for the size and shape of the NS and their drug release pattern.

\section{8. In-Vitro Drug Release}

The dissolution behavior of EE coarse powder and lyophilized EENPs in a simulated gastric fluid is shown in Fig.10. The dissolution rates of EE and EENPs in the simulated gastric fluid were $26.20 \%$ and $95.10 \%$ respectively. 
The EENPs showed a dramatic increase in dissolution rate as compared to EE coarse powder. Moreover, the EENPs displayed a marked increase in dissolution rate, more than $60 \%$ as compared to EE coarse powder (15\%) within 60 $\min$.

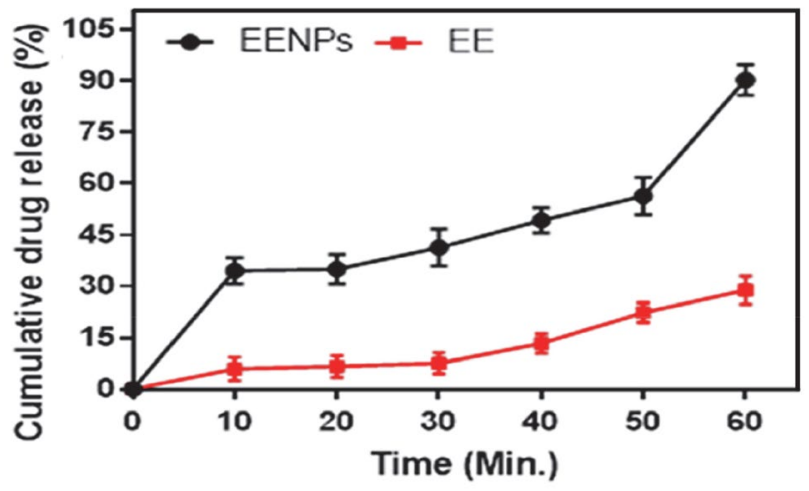

Figure 10. Dissolution profiles of optimized nanosuspension (EENPSs) with a pure drug in simulated gastric fluid.

These suggested that the dissolution profile of lyophilized EENPs were distinctly superior as compared to EE. The dissolution enhancement of drug could be initiated to reduced particle size, especially in nanometre range with an effective increase in surface area which is available to get dissolved. This phenomenon is better explained by Noyes-Whitney equation.

$$
\frac{d C}{d t}=D S-\frac{C_{S}-C_{t}}{\mathrm{~h}}
$$

where $\mathrm{h}$ denotes the thickness of the dissolution boundary layer, $\mathrm{D}$ is the diffusion coefficient of the solute, Cs is the saturation solubility, $\mathrm{S}$ represents the surface area, $\mathrm{dC} / \mathrm{dt}$ represents the dissolution rate and $\mathrm{Ct}$ is the bulk concentration. As the particle size of EENPs was much smaller than that of EE, hence they have a much larger surface area, hence higher dissolution rate.

Besides the particle size, the shape also plays a vital role that may affect the dissolution of the drug. Particles that are irregular, flaky and long may increase its average hydrodynamic thickness at the boundary layer. Thus, the value of $\mathrm{h}$ would be increased with a decrease in dissolution rate. The SEM image of EE showed rod-shaped particles in different sizes. Thus concluded enhancement in dissolution was due to the particle size reduction than that of shape alteration. ${ }^{36}$

\section{9. Pharmacokinetic and Biodistribution Study in Sprague- Dawley Rats}

In order to confirm the positive impact of NS on oral bioavailability enhancement of EE, in-vivo PK studies of EENPs and EEAQD were carried out in rats, and results obtained were compared with each other. The mean EE
Table 11. Pharmacokinetic parameters of EEAQD and lyophilized EENPS in Sprague- Dawley rats.

\begin{tabular}{crr}
\hline $\begin{array}{c}\text { Pharmacokinetic } \\
\text { parameter }\end{array}$ & \multicolumn{1}{c}{ EEAQD } & Lyophilized EENPs \\
\hline $\mathrm{C}_{\text {max }}(\mathrm{ng} / \mathrm{mL})$ & $946.34 \pm 1.23$ & $1837.30 \pm 1.65^{\star *}$ \\
$\mathrm{~T}_{\max }(\mathrm{h})$ & $4.00 \pm 1.45$ & $6.00 \pm 1.47^{\star *}$ \\
$\mathrm{t}_{1 / 2}(\mathrm{~h})$ & $20.75 \pm 1.36$ & $14.10 \pm 1.33^{\star *}$ \\
$\mathrm{MRT} \mathrm{h})$ & $29.95 \pm 2.01$ & $20.35 \pm 2.01^{\star *}$ \\
$\mathrm{AUC}_{0-\mathrm{t}}\left(\mathrm{ng} / \mathrm{mL}^{\star} \mathrm{h}\right)$ & $12290.12 \pm 4.25$ & $0777.17 \pm 3.14^{\star *}$ \\
$\mathrm{AUC}_{0-\infty}\left(\mathrm{ng} / \mathrm{mL}^{\star} \mathrm{h}\right)$ & $15187.72 \pm 4.56$ & $22950.52 \pm 3.45^{\star *}$ \\
$\mathrm{VD}(\mathrm{mL})$ & $0.00588 \pm 2.42$ & $0.00122 \pm 2.33^{\star *}$ \\
$\mathrm{Cl}\left(\mathrm{mL} \mathrm{h}^{-1}\right)$ & $1.97 \times 10^{-5} \pm 2.55$ & $6.016 \times 10^{-5} \pm 2.65^{\star *}$ \\
$\mathrm{KE}\left(\mathrm{h}^{-1}\right)$ & $0.0334 \pm 2.45$ & $0.04915 \pm 2.45^{\star *}$ \\
$\mathrm{~F}_{\text {rel }}$ & - & $1.70 \pm 1.05$ \\
\hline a** $\mathrm{P}<0.01$, compared to the corresponding parameters of EEAQD. \\
Results were expressed as the mean $\pm \mathrm{SD}(\mathrm{n}=3)^{\mathrm{a}}$
\end{tabular}

concentration-time profile in the rat plasma is shown in Fig. 11, after oral administration of a single dose of $0.5 \mathrm{mg} /$ $\mathrm{kg}$ of EE from EENPs and EEAQD and their PK parameters obtained are reported in Table 11.

Following oral administration of EENPs and EEAQD, the plasma concentration of EE from EENPs in rats was significantly reached to a higher level than that of EE$A Q D$ at every time interval. The EENPs exhibited higher $\mathrm{C}_{\max }$, which indicates greater drug absorption. The $\mathrm{C}_{\max }$ of EENPs is increased by $\sim 2$ folds. The reduced $\mathrm{C}_{\max }$ of EEAQD is due to rapid distribution and metabolism of EE. The coating of soya lecithin helps the circulation of formulation in the body for a prolonged period, thus $T_{\max }$ of EENPs is higher than EEAQD. The relative bioavailability of EENPs was found to be 1.70 as compared to EEAQD. The area under the curve (AUC) is a vital PK parameter that explains the circulation and exposure time of the drug in bloodstreams. ${ }^{43}$ The $\mathrm{AUC}_{0-\mathrm{t}}$ of EENPS and EEAQD were $20777.18 \mathrm{ng} / \mathrm{mL}^{\star} \mathrm{h}$ and $12290.12 \mathrm{ng} / \mathrm{mL}^{\star} \mathrm{h}$, respectively. These increase in AUC indicated that the EE

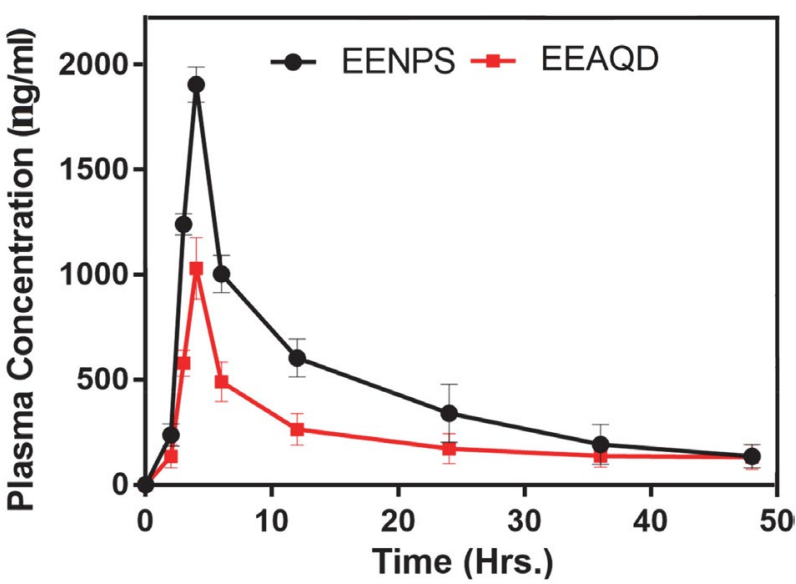

Figure 11. Plasma concentration-time profiles of EE after oral administration of EENPS and the EEAQD formulation in rats. Each value represents the mean \pm S.D. $(n=3)$. 
oral absorption in rats was enhanced notably in lyophilized NS form. Thus oral bioavailability of EE was improved by decreased particle size, enhanced membrane permeation and increased dissolution rate. As a stabilizer moreover, soya lecithin (phospholipids) has a thick coat on the surface of EENPs, which also plays a vital role in bioavailability enhancement. It is an amphiphilic surfactant, that may enhances EE penetration ability and thus promote rapid permeation of the $\mathrm{EE}$ nanoparticles through the intestinal epithelium, and finally into the systemic circulation. ${ }^{34}$

After oral administration, biodistribution study of EENPs and EEAQD showed the higher collection of EE in spleen, liver, stomach, and kidney. Fig. 12, revealed the maximum concentration of EE by liver, spleen, stomach, and kidney were $1485.71 \pm 5.56,1122.43 \pm 4.88,1323.63 \pm$ 5.62 and $891.16 \pm 5.33 \mathrm{ng} / \mathrm{g}$, for EENPs, respectively, after $48 \mathrm{~h}$ of oral administration. However, the EEAQD concentration in spleen, liver, stomach, and kidney were $745.62 \pm$ $3.78,956.89 \pm 4.56,821.23 \pm 5.02$ and $652.35 \pm 3.78 \mathrm{ng} / \mathrm{g}$, respectively. This may be due to the faster elimination of EE due to higher particle size as compared to EENPs. The higher uptake of EE in spleen, liver, and stomach is may be

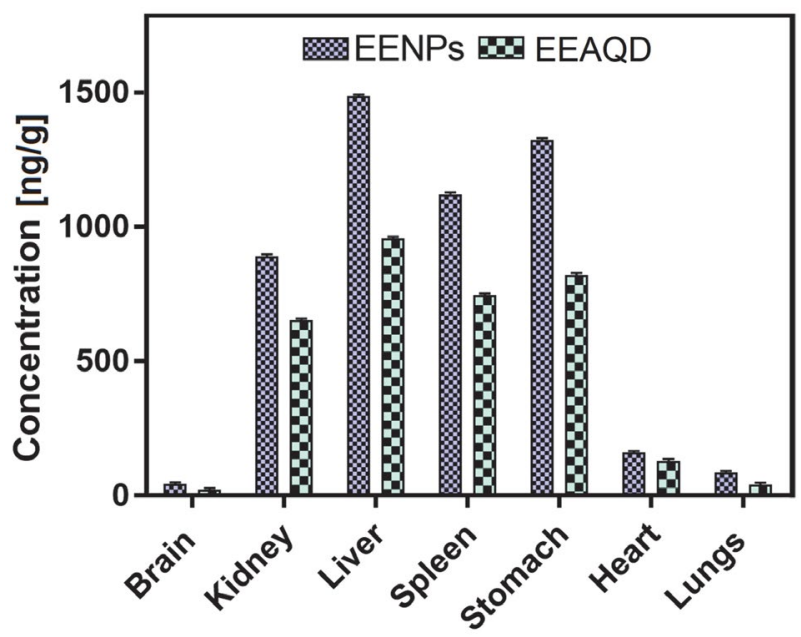

Figure 12. Biodistribution of EENPS and EEAQD after oral administration in rats brain, kidney, liver, spleen, stomach, heart, lungs. due to enhanced lymphatic uptake. The concentration of EENPs in the brain was $43.56 \pm 4.05 \mathrm{ng} / \mathrm{g}$ and EEAQD was $22.46 \pm 4.35 \mathrm{ng} / \mathrm{g}$, respectively. The concentration of EE in lungs and heart were $86.82 \pm 3.02$ and $160.48 \pm 3.56 \mathrm{ng} / \mathrm{g}$ for EENPs, while for EEAQD it was $42.65 \pm 4.33$ and $130.56 \pm 3.98 \mathrm{ng} / \mathrm{g}$ respectively. Comparison of EEAQD with EENPs was not statistically significant ( $p>0.05$ ). Thus, biodistribution studies conclude the accumulation of EENPs in spleen, liver, stomach and kidneys in a larger amount as compared to the brain, lungs, and heart. ${ }^{44}$

\section{10. Stability Studies}

The six-month stability data for EENPs and liquid EENPs is presented in Table 12. NS stored at room temperature showed an increased particle size from $220 \mathrm{~nm}$ to $316 \mathrm{~nm}$ over 6 months. Storage at refrigerated conditions showed a nominal increase from $220 \mathrm{~nm}$ to $275 \mathrm{~nm}$ indicating better stability. NS stored at $40 \pm 2{ }^{\circ} \mathrm{C} / 75 \pm 5 \%$ relative humidity (RH) showed an increased particle size from $220 \mathrm{~nm}$ to $315 \mathrm{~nm}$. The observations conclude that temperature influences the aggregation of EE nanoparticles, and hence it was higher at RT and above compared to refrigerator conditions. Significant aggregation was more likely to occur in liquid EENPs compared to lyophilized EENPs at all storage conditions. Refrigerated conditions do not have a significant effect on average particle size, whereas at room temperature and $40 \pm 2{ }^{\circ} \mathrm{C}$ there was a significant effect. Thus it can be concluded that at higher temperatures particle aggregation takes place which might lead to the increased size of particles and thus makes them less stable. Probably Ostwald ripening may be the second reason resulting from fluctuations at room temperature. The results obtained from the chemical stability of formulation upon storage at different conditions are also presented in Table 10. Results suggest no significant change in EE content of liquid EENPs and lyophilized EENPs when stored at different storage conditions indicating that both the liquid and lyophilized NS are chemically stable at these storage conditions. Noteworthy, for physical stability of liquid EENPs, lyophilization and storage at refrigerated condition are recommended. ${ }^{39}$

Table 12. Stability data of lyophilized EENPS and EENPS for the six-month stability study.

\begin{tabular}{|c|c|c|c|c|c|c|c|c|c|}
\hline \multirow[t]{2}{*}{ Formulation } & \multirow{2}{*}{$\begin{array}{c}\text { Storage } \\
\text { Temperature } \\
\text { Conditions }\end{array}$} & \multirow{2}{*}{$\begin{array}{c}\text { Initial } \\
\text { Particle } \\
\text { Size }\end{array}$} & \multicolumn{3}{|c|}{$\begin{array}{c}\text { Particle Size } \\
\text { After }\end{array}$} & \multirow{2}{*}{$\begin{array}{l}\text { Initial } \\
\text { drug } \\
\text { content }\end{array}$} & \multicolumn{3}{|c|}{$\begin{array}{l}\text { Drug content } \\
\text { After }\end{array}$} \\
\hline & & & $2 \mathrm{M}$ & $4 \mathrm{M}$ & $6 \mathrm{M}$ & & $2 \mathrm{M}$ & $4 \mathrm{M}$ & $6 \mathrm{M}$ \\
\hline & & & & & & & & & \\
\hline EE NPs & R. T. & & $256.5 \pm 9.1$ & $293.5 \pm 4.6$ & $316.2 \pm 4.7$ & & $90.56 \pm 0.56$ & $89.02 \pm 0.62$ & $88.63 \pm 0.74$ \\
\hline & $40^{\circ} \pm 2^{\circ} \mathrm{C}$ & & $260.4 \pm 8.1$ & $286.9 \pm 5.6$ & $315.4 \pm 5.6$ & & $90.88 \pm 0.96$ & $89.45 \pm 0.89$ & $88.03 \pm 0.97$ \\
\hline Liquid & $4^{\circ} \mathrm{C}$ & & $212.5 \pm 9.1$ & $225.8 \pm 4.6$ & $238.9 \pm 7.5$ & & $95.20 \pm 0.58$ & $94.65 \pm 0.65$ & $93.33 \pm 0.66$ \\
\hline EE NPs & $\begin{array}{c}\text { R. T. } \\
40^{\circ} \pm 2^{\circ} \mathrm{C}\end{array}$ & $209.4 \pm 10.3$ & $\begin{array}{l}268.9 \pm 7.7 \\
270.4 \pm 8.1\end{array}$ & $\begin{array}{l}308.9 \pm 7.1 \\
299.2 \pm 5.5\end{array}$ & $\begin{array}{l}334.8 \pm 8.8 \\
322.9 \pm 5.6\end{array}$ & $96.48 \pm 0.66$ & $\begin{array}{l}93.25 \pm 0.47 \\
93.33 \pm 0.33\end{array}$ & $\begin{array}{l}91.41 \pm 0.48 \\
92.00 \pm 0.54\end{array}$ & $89.63 \pm 0.41$ \\
\hline
\end{tabular}

${ }^{*} \mathrm{M}=$ Months 


\section{Conclusion}

Stable lyophilized NS of EE was developed and evaluated using the $\mathrm{QbD}$ approach with enhanced bioavailability. The $\mathrm{QbD}$ approach was applied to understand the effect of CMAs and CPPs on CQAs and to improve the quality and safety of formulation. The impact of process and formulation variables that affect CQAs of NS, and influence stability and solubility of EE in NS, were optimized using statistical experimental designs viz., Plackett-Burman and Central Composite design within a $\mathrm{QbD}$ concept. It was manifested from the design, that the selected variables, i.e. no. of cycles of HPH, the concentration of soya lecithin, and concentration of tween 80 had a keen impact on characteristics of NS. The predicted values obtained from designs were comparable with observed ones. The optimized factors were applied to develop highly stable NS of EE with the remarkable enhancement of dissolution rates and stability. The particle size distribution pattern of optimized product from CCD overlay plot showed an average particle size of $220 \pm 0.37 \mathrm{~nm}$ with a zeta potential of $-19.3 \pm 6.73 \mathrm{mV}$. Dissolution velocity and release rate of EENPs was increased significantly, due to reduced particle size and increased surface area of EE. The lyophilized NS was found to be stable when stored in the refrigerator. The plasma pharmacokinetic parameters including $\mathrm{C}_{\max }, \mathrm{T}_{\max }$, and AUC total, of EENPs on rats were significantly higher than those of EEAQD. The relative bioavailability of EENPs was enhanced by more than 2 folds. Biodistribution study suggests that higher concentration of EE was found in the liver within $72 \mathrm{~h}$. Thus, lyophilized EENPS could be a promising aspect in clinical application for cancer as well as contraceptive agents with enhanced bioavailability and stability.

Furthermore, with the application of QbD concept in this study, very few experimental runs are used for the optimization of NS which are the evidence for the reduction of manufacturing cost, while the least values of residual error obtained are the evidence for reduction of manufacturing variability. Small particle size, least PDI values, higher drug content, smooth and spherical particles with higher entrapment efficiency and enhanced bioavailability confirms the desired quality of EE nanosuspension. On the basis of the results obtained as evidence, it can be concluded that QbD is a helpful tool in NDDS to reduce the manufacturing variability, improve the quality and safety, and to reduce the manufacturing cost, which is a primary requirement by USFDA.

\section{Acknowledgment}

The authors are grateful to Dr. Babasaheb Ambedkar Research and Training Institute (BARTI), Pune for providing funds to carry out the research work smoothly. All authors would like to acknowledge Dr. H. N. More, Principal,
Bharati Vidyapeeth College of Pharmacy, Kolhapur for providing the necessary facilities for the smooth working of the research project.

\section{Conflict of interest}

The authors declare no conflict of interest. The authors alone are responsible for the content and writing of the article.

\section{References}

1. G. Evans, E. L. Sutton EL, Med. Clin. North. Am., 2015, 99, 479-503. DOI:10.1016/j.mcna.2015.01.004

2. C. L. Williams, G. M. Stancel, The Pharmacological basis of therapeutics, in : A. G. Gilman, L. S. Goodman, T. W. Rall, F. Murad (Eds.), Estrogens and Progestins, McGraw Hill., New York, 2018, pp. 1420-1421.

3. L. Speroff, P. D. Darney, Contraception Clinical Guide for Contraception, fifth ed., Wolters Kluwer Health, New York, 2010.

4. A. Pellegrini, B. Massidda, V. Mascia, M. T. Ionta, M. G. Lippi, A. Muggiano, E. Carboni, G. Robustelli della Cuna, G. Bernardo, M. R. Strada, L. Pavesi, Cancer Treat. Rep., 1981, 65(1-2), 135-6.

5. A. Sueta, M. Hayashi, Y. Fukugawa, H. Shimizu, Y. I. Mutsuko, Y. Yamamoto, H. Iwase H, Int. Cancer Conf. J., 2016, 5(3), 126-130. DOI:10.1007/s13691-015-0241-7

6. J. T. Herjan, C. Bennink, C. Verhoeven, J. Thijssen. Maturitas., 2017, 95, 11-23. DOI:10.1016/j.maturitas.2016.10.010

7. H. Iwase, Y. Yamamoto, M. Yamamoto-Ibusuki, K. I. Murakami, Y. Okumura, S. Tomita, T. Inao, Y. Honda, Y. Omoto, K. I. Iyama, Br. J. Cancer., 2013, 109, 1537-1542. DOI:10.1038/bjc.2013.520

8. A. Agrawal, J. R. F. Robertson, K. L. Cheung, World J. Surg. Oncol., 2006, 4, 44. DOI:10.1186/1477-7819-4-44

9. K. Izumi, Y. Kadono, T. Shima, H. Konaka, A. Mizokami, E. Koh, M. Namiki, Anticancer Res., 2010, 30(12), 5201-5.

10. H. C. Bennink, M. Visser, Estetrol (E4), the forgotten fetal steroid. Proceedings of the 9th European Congress of Endocrinology, Budapest, Hungary, April 28- May 02, 2007. European Society of Endocrinology: 2007.

11. P. V. Isabela, J. S. Daniel, C. C. Eduardo, J. S.Garcia, M. G. Trevisan., J. Therm. Anal. Calorim., 2015, 120 (1), 573-581. DOI:10.1007/s10973-015-4508-1

12. A. Sattar, D. Chen, L. L. Jiang, Y. Pan, Y. Tao, L. Huang, Z. Liu, S. Xie, Z. Yuan, Scientific Reports., 2017, 7, 1-9. DOI:10.1038/s41598-017-02523-4

13. M. Garg, D. Mishra , H. Agashe, N. K. Jain, J. Pharm. Pharmacol., 2006, 58, 459-468. DOI:10.1211/jpp.58.4.0005

14. T. Zhang, J. Murowchick, B. B. Youan, J. Pharm. Sci., 2011, 100 (3), 1031- 44. DOI:10.1002/jps.22341

15. E. M. Merisko-Liversidge, G. G. Liversidge, Toxicol. Pathol., 2008, 36 (1), 43-8. DOI:10.1177/0192623307310946

16. P. Sharma, W. A. Denny, S. Garg, Int. J. Pharm., 2009, 380 (1-2), 40-8. DOI:10.1016/j.ijpharm.2009.06.029 
17. R. Lobenberg, G. L. Amidon, Eur. J. Pharm. Biopharm., 2000, 50 (1), 3-12. DOI:10.1016/S0939-6411(00)00091-6

18. F. Lai, C. Sinico, G. Ennas, F. Marongiu, G. Marongiu, A. M. Fadda, Int. J. Pharm., 2009, 373 (1-2), 124-32.

DOI:10.1016/j.ijpharm.2009.01.024

19. V. R. Patel, Y. K. Agrawal, J. Adv. Pharm. Techol. \& Res., 2011, 2 (2), 81-87. DOI:10.4103/2231-4040.82950

20. F. Kesisoglou, S. Panmai, Y. Wu, Adv. Drug. Deliv. Rev., 2007, 59 (7), 631-644. DOI:10.1016/j.addr.2007.05.003

21. D. Gol, S. Thakkar, M. Misra, Drug Dev. Ind. Pharm., 2018, 44 (9), 1458-1466. DOI:10.1080/03639045.2018.1460377

22. L. Gao, G. Liu, J. Ma, X. Wang, L. Zhou, X. Li, J. Control Release., 2012, 160 (3), 418-30.DOI:10.1016/j.jconrel.2012.03.013

23. Y. Gao, Z. Li, M. Sun, C. Guo, A. Yu, Y. Xi, J. Cui, H. Lou, G. Zhai, Drug Deliv., 2011, 18(2), 131-142.

DOI: $10.3109 / 10717544.2010 .520353$

24. L. Hao, X. Wang, D. Zhang, Q. Xu, S. Song, F. Wang, C. Li, H. Guo, Y. Liu, D. Zheng, Q. Zhang, Int. J. Pharm., 2012, 433 (1-2), 157-64. DOI:10.1016/j.ijpharm.2012.05.002

25. Q. Huang, H. Yu, Q. Ru, J. Food Sci., 2010, 75, 50-57.

DOI:10.1111/j.1750-3841.2009.01457.x

26. R. H. Müller, K. Peters, Int. J. Pharm., 1998, 160, 229-237. DOI:10.1016/S0378-5173(97)00311-6

27. S. A. Maskarinec, J. Hannig, R. C. Lee, K. Y. C. Lee, Biophys. J., 2002, 82 (3), 1453-9.

DOI:10.1016/S0006-3495(02)75499-4

28. M. Trotta, M. Gallarate, F. Pattarino, S. Morel, J. Control Release., 2001, 76 (1-2), 119-28.

DOI:10.1016/S0168-3659(01)00432-1

29. F. Yerlikaya, A. Ozgen, I. Vural, O. Guven, E. Karaagaoglu, M. A. Khan, Y. Capan, J. Pharm. Sci., 2013, 102, 3748-3761. DOI:10.1002/jps.23686

30. N.S. K. Srinivas, R. Verma, G. P. Kulyadi, L. Kumar, Int. J. Nanomed., 2017, 12, 15-28. DOI:10.2147/IJN.S122729
31. J. Cook, M. T. Cruañes, M. Gupta, S. Riley, J. Crison, AAPS Pharm. Sci. Tech., 2014, 15 (1),140-148.

DOI:10.1208/s12249-013-0043-1

32. H. C. Vadlamudi, P. R. Yalavarthi, B. R. Venkata, J. Thanniru, K. R. Vandana, C. R. Sundaresan, J. Acute. Dis., 2016, 5(4), 315-325. DOI:10.1016/j.joad.2016.05.004

33. C. P. Dora, S. K. Singh, S. Kumar, A. K. Datusalia , A. Deep, Acta Pol. Pharm. (dnlm), 2010, 67(3), 283-290.

34. S. Kalvakuntla, M. Deshpande, Z. Attari, K. Kunnatur, $A d v$. Pharm. Bull., 2016, 6(1), 83-90. DOI:10.15171/apb.2016.013

35. L. Rabelo, N. Monteiro, R. Serquiz, P. Santos, R. Oliveira, A. Oliveira, H. Rocha, A. H. Morais, A. Uchoa, E. Santos, Mar. Drugs., 2012, 10, 727-743. DOI:10.3390/md10040727

36. J. He, Y. Han, G. Xu, L. Yin, N. M. Neubi, J. Zhou, D. Yang, RSC Adv. 2017, 7, 13053-13064. DOI:10.1039/C6RA28676C

37. S. R. Shah, R. H. Parikh, J. R. Chavda, N. R. Sheth, Powder Technol., 2013, 235, 405-411. DOI:10.1016/j.powtec.2012.10.055

38. P. F. Yue, Q. Zheng, B. Wu, P. Y. Hu, Z. F. Wu, M. J. Yan, J. Disper. Sci. Technol., 2012, 33, 213-222.

DOI:10.1080/01932691.2011.561162

39. L. Vuppalapati, S. Cherukuri, V. Neeli, R. P. Yeragamreddy, B. R. Kesavan, Curr. Drug Deliv., 2016, 13, 143-157. DOI:10.1080/01932691.2011.561162

40. V. M. Pandya, J. K. Patel, D. J. Patel, Disso. Technol., 2011, 40-45. DOI:10.14227/DT180311P40

41. A. A. Abdelbary, A. M. Al-mahallawi, M. E. Abdelrahim, M. A. Ali, Int. J. Nanomed. 2015,10(1),6339-6353. DOI:10.2147/ IJN.S91631

42. V. Borhade, S. Pathak, S. Sharma, V. Patravale, Nanomed (Lond)., 2014, 9(5),649-66. DOI:10.2217/nnm.13.61

43. I. Ghosh, B. Michniak-Kohn, AAPS Pharm. Sci. Tech., 2013, 14(3), 1108-1117. DOI:10.1208/s12249-013-9995-4

44. M. Bagad, Z. A. Khan, Int. J. Nanomed., 2015, 10, 3921-3935. DOI:10.2147/IJN.S80706

\section{Povzetek}

Liofilizirano nanosuspenzijo slabo topnega etinilestradiola (EE) smo pripravili z namenom izboljšanja topnosti in biološke uporabnosti s pristopom »Quality by Design«(QbD). S pomočjo diagrama Ishikawa smo z načrtovanjem Placket-Burman identificirali in pregledali potencialne dejavnike tveganja, da bi raziskali učinke formulacijskih in procesnih spremenljivk na odvisne spremenljivke. Število ciklov (X4), koncentracija sojinega lecitina (X5) in koncentracija stabilizatorja »tween 80 « (X7) so bili opredeljeni kot pomembni dejavniki $(\mathrm{P}<0,05)$, ki smo jih dodatno optimizirali z uporabo »Central Composite Design«. Srednja velikost delcev, zeta potencial, vsebnost zdravila in učinkovitost enkapsuliranja optimizirane liofilizirane EE nanosuspenzije (EENP) je bila $220 \pm 0,37 \mathrm{~nm},-19,3 \pm 6,73 \mathrm{mV}, 92,23 \pm 0,45 \%, 99,52 \pm$ $0,52 \%$. EENP znatno poveča Cmax in $\mathrm{AUC}_{0-\mathrm{t}}$ za $1,5,1,7$ krat in relativno biološko uporabnost za dvakrat, pri čemer je njegova porazdelitev v višjih koncentracijah v jetrih, vranici in želodcu. Razvoj nanosuspenzij, ki temelji na QbD pristopu, bi lahko uporabili za prepoznavanje kritičnih procesnih parametrov in atributov za določanje kakovosti.

Except when otherwise noted, articles in this journal are published under the terms and conditions of the Creative Commons Attribution 4.0 International License 